\title{
Tres Repúblicas Barriales y sus Universidades. Las Universidades Populares en la ciudad de Buenos Aires en el período de entreguerras: un esquema preliminar $^{*}$
}

\section{Alejandro Martín YaverovsKI}

Afiliado institucionalmente a Alternativas pedagógicas y prospectiva educativa en América Latina APPEAL (Argentina). Correo electrónico: alejandroyave@gmail.com. El autor es profesor en Enseñanza Media y Superior en Historia, por la Universidad de Buenos Aires (Argentina). Entre sus publicaciones recientes tenemos: "Cien años de oscuridad sobre las Universidades Populares: a cien años del chispazo de la Reforma Universitaria en Córdoba", Encuentro de Saberes No. 8 (2018) y "Universidades populares: la búsqueda de la genealogía propia”, Signos y Sentidos No. 19 (2018). Entre sus temas de interés se encuentran Historia de la Educación en América Latina, Universidades Populares.

Recibido: 29 de marzo de 2019

Aprobado: 23 de julio de 2019

Modificado: 7 de agosto de 2019

Artículo de investigación científica

DOI: https://doi.org/10.15648/hc.38.2021.2817

Este artículo forma parte del proyecto "Historia de la educación en América Latina: sujetos y prácticas en las fronteras de la educación formal (1910-1970) (UBACYT)” financiado por el Instituto de Investigaciones de Ciencias de la Educación, Universidad de Buenos Aires (Argentina).

Esta publicación está bajo una licencia Creative Commons Reconocimiento-NoComercial 4.0 (cc) BY-NC

Agradezco las observaciones y los comentarios vertidos por Gabriela Ossenbach y por los colegas evaluadores, que me ayudaron a mejorar este texto e hicieron posible que fuera publicable. Las deficiencias que conserva son de mi total responsabilidad. 
Tres Repúblicas Barriales y sus Universidades. Las Universidades Populares en la ciudad de Buenos Aires en el período de entreguerras: un esquema preliminar

\section{Resumen}

Este trabajo aporta una nueva perspectiva al conocimiento histórico de las Universidades Populares. Para ello se analiza la experiencia de tres instituciones de la ciudad de Buenos Aires: la Universidad Popular de La Boca, fundada en 1917; la Universidad Popular de Boedo, cuya fundación data de 1928; y la Sociedad Luz Universidad Popular, creada en 1899 por iniciativa del Partido Socialista, y actualmente emplazada en el barrio porteño de Barracas.

Dichas instituciones educativas son estudiadas en relación con el concepto dual de barrio, propio del desarrollo de la historia local de la ciudad de Buenos Aires. Se trabaja como hipótesis que la pertenencia a "lo barrial" -enunciada incluso desde su nomenclatura en dos de los casos- influyó en la constitución de las identidades de los barrios y de las Universidades Populares, así como en el despliegue de una red de vínculos barriales.

Palabras clave: Universidad Popular, barrio, Buenos Aires, educación popular, redes.

Three Neighborhood Republics and their Universities. People's Universities in the city of Buenos Aires in the interwar period: a preliminary outline

\section{Abstract}

This article brings a new perspective to the historical knowledge of the People's Universities. To this end, the experiences of three institutions in the city of Buenos Aires are analyzed: the People's University of La Boca, founded in 1917; the People's University of Boedo, whose foundation dates from 1928; and the People's University "Sociedad Luz", created in 1899 on the initiative of the Socialist Party and currently located in the Buenos Aires neighborhood of Barracas.

These educational institutions are studied in relation to the dual concept of neighborhood, typical of the development of the local history of the city of Buenos Aires. We work as a hypothesis that belonging to "the neighborhood" - enunciated even in the denomination of two of the People's Universities- influenced the consti- 
tution of the identities of both neighborhoods and People's Universities, fostering the development of a network of links between neighborhoods.

Key words: People's Universities, neighborhoods, Buenos Aires, popular education, networks.

Três Repúblicas de bairros e suas Universidades. As Universidades Populares na cidade de Buenos Aires no período entre guerras: um esquema preliminar

\section{Resumo}

O trabalho traz uma nova perspectiva para o conhecimento histórico das Universidades Populares. Para isso, analisa-se a experiência de três instituições na cidade de Buenos Aires: a Universidade Popular da Boca, fundada em 1917; a Universidade Popular de Boedo, cuja fundação data de 1928; e a Sociedade Luz Universidade Popular, criada em 1899 por iniciativa do Partido Socialista, atualmente localizada no bairro de Barracas, em Buenos Aires.

Estas instituições educacionais são estudadas em relação ao conceito dual de bairro, típico do desenvolvimento da história local da cidade de Buenos Aires. Trabalhamos como uma hipótese de que pertencer ao "bairro" -anunciado até mesmo a partir de sua nomenclatura em dois dos casos- influenciou a constituição das identidades de bairros e Universidades Populares, assim como a implantação de uma rede de ligações dos bairros.

Palavras-chave: Universidade Popular, bairro, Buenos Aires, educação popular, redes.

Trois Républiques Communautaires et leurs universités. Les Universités Populaires dans la ville de Buenos Aires dans l'entre deux-guerres: première ébauche

\section{Résumé}

Cet article apporte une nouvelle perspective aux connaissances historiques des universités populaires. À cette fin, les expériences de trois institutions de la ville de Buenos Aires sont analysées: l'Université populaire de La Boca, fondée en 1917; l'Université populaire de Boedo, dont la fondation date de 1928; et l'Université populaire «Sociedad Luz», créée en 1899 à l'initiative du Parti socialiste et actuel- 
lement située dans le quartier de Barracas à Buenos Aires.

Ces établissements d'enseignement sont étudiés sous l'angle du double concept de quartier, caractéristique du développement de l'histoire locale de la ville de Buenos Aires. Nous travaillons comme une hypothèse selon laquelle lappartenance au «quartier» - même dans la dénomination de deux des universités populaires a influencé la constitution de lidentité des quartiers et des universités populaires, favorisant ainsi le développement d’un réseau de liens entre quartiers.

Mots clés: Universités Populaires, quartiers, Buenos Aires, éducation populaire, réseaux.

\section{INTRODUCCIÓN}

Buenos Aires no es una ciudad, sino un conjunto de ciudades

yuxtapuestas.

Federico Rahola y Tremols (1905)

Este artículo analiza la presencia de tres Universidades Populares (UUPP) en el período de entreguerras, en una ciudad que podemos considerar de nueva formación ${ }^{2}$, producto de la expansión territorial y de los ritmos acelerados de cambios que atravesaba, desde los nuevos asentamientos, la reconfiguración de los viejos, el desarrollo de nuevas industrias, la desaparición de algunas ramas industriales, etcétera.

Las complejidades de brindar una definición categorial de lo que son las "Universidades Populares" fueron tratadas en otros trabajos con anterioridad. A los efectos de este trabajo, de modo sintético podemos afirmar que las Universidades Populares fueron y son instituciones que brindaban una forma particular de educación popular, con diversas estrategias pedagógicas hacia un público también diverso, compuesto mayormente por trabajadores y trabajadoras adultos, sin exclusión de

1 Federico Rahola, Sangre Nueva. Impresiones de un viaje á la América del Sud (Barcelona: Tipografía "La Académica", 1905), 89.

2 Luciano de Privitellio, Vecinos y ciudadanos. Política y sociedad en la Buenos Aires de entreguerras (Buenos Aires: Siglo Veintiuno, 2003). 
otros sectores que no contaban con fácil acceso a otras instancias de formación ${ }^{3}$.

Las tres UUPP a las que nos referiremos (ubicadas en La Boca, Boedo y Monserrat), se encontraban en barrios de Buenos Aires que pueden considerarse como el "sur arrabalero" y obrero de la ciudad. Canalizaron tanto los anhelos de los sectores subalternos como los temores de las élites, en épocas en que el puerto de Buenos Aires era la entrada que daba la bienvenida tanto a los sueños de un ingente número de inmigrantes que llegaban con la esperanza de "hacer la América" como a los conflictos que tanto temían las elites y escondían detrás del rótulo de la "cuestión social".

Para hacer el cruce entre identidad barrial y la presencia de las Universidades Populares nos nutriremos de una serie de textos periodísticos redactados por Juan José de Soiza Reilly para la revista Caras y Caretas entre 1930 y 1931, en los cuales se retratan catorce barrios de la ciudad de Buenos Aires. De Soiza Reilly fue un periodista de larga trayectoria y activo promotor de las UUPP en Argentina ${ }^{4}$. Estas crónicas pueden considerarse un significativo aporte a la construcción de la idea de barrio o, como lo enuncia su autor, la idea de "barrio-república", en el contexto de la consolidación de la segunda generación de barrios de Buenos Aires. El material aquí analizado consiste de dos notas publicadas entre septiembre de 1930 y febrero de 1931, con el título serial de "Viaje a través de los barrios de Buenos Aires", donde compone parte del retrato barrial y sus instituciones, haciendo una particular mención a las educativas -las Universidades de Boedo y de La Boca-.

La ciudad de Buenos Aires está situada en la región centro-este del país, sobre la orilla occidental del Río de la Plata, en la región pampeana. Promediando el año 1870 Buenos Aires era una ciudad mediana, de no más de unos 180.000 habitantes, cuyo radio alcanzaba apenas unas cuantas cuadras más allá del centro tradicional. Luego de la federali-

$3 \quad$ Alejandro Martín Yaverovski, "Dos palabras ¿Un concepto? Mil y un Concepciones para reflexionar en torno a los 100 años de las Universidades Populares". (Ponencia presentada en las Jornadas "Memorias, legados, disputas y prospectivas en Historia de la Educación. A 100 años de la Reforma Universitaria". Córdoba: Universidad Nacional de Córdoba, 2018).

4 Juan De Soiza Reilly (Concordia, provincia de Entre Ríos, 19 de mayo de 1880 - Buenos Aires, 19 de marzo de 1959). 
zación de la ciudad (1880), Buenos Aires creció aceleradamente hasta promediar los años cuarenta del siglo XX. Mientras que en 1887 contaba con menos de medio millón de habitantes, en 1947 casi alcanzaba los tres millones ${ }^{5}$.

Los límites jurisdiccionales de la ciudad de Buenos Aires para 1910, año del centenario de la Argentina, ya se encontraban estabilizados y eran los mismos que los actuales, tal como lo revela el mapa del centenario ${ }^{6}$. Nos referimos a los límites con la Provincia de Buenos Aires por el sur, en las aguas del Riachuelo, mientras que por el oeste y el norte el límite lo demarcaba la Avenida General Paz, y por el noreste y parte del este, el Río de la Plata.

Los barrios más antiguos de la ciudad derivan, en su mayoría, de

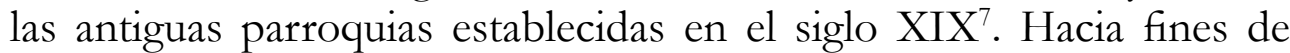
ese siglo surge una nueva generación de barrios determinados por diversos orígenes. Cada barrio tiene una historia local propia y características poblacionales determinadas que le imprimen un color, estilo y costumbres únicas, reflejando la variedad cultural de la ciudad, que está lejos de ser un bloque homogéneo, aunque mantiene características identitarias que funcionan de argamasa, permitiendo reconocerla como una unidad. De este modo no pierde vigencia la frase citada al comienzo, y pronto se deja descubrir, al conocer más de sus barrios, que esta ciudad no es una ciudad sino muchas y yuxtapuestas.

5 La literatura reflejó este notable crecimiento demográfico y transformación, en obras como: La gran aldea (1882), de Lucio Vicente López; La bolsa (1890), de José María Miró (Julián Martel); El diario de Gabriel Quiroga (1910), escrito por Juan Gabriel Gálvez, y particularmente para el caso del barrio de La Boca, Evocaciones Boquenses (1952), de José María Brignone.

6 Oficina Cartográfica Bemporat y A. Bemporat (comp.), Plano centenario de la Capital Federal: plano de conjunto del catastro de la Capital, 1816-1916 (Buenos Aires: Oficina Cartográfica Bemporat, 1916).

7 Una descripción de la ciudad y sus barrios durante el siglo XIX, en Gabriel Di Meglio, ;Viva el bajo pueblo! La plebe urbana de Buenos Aires y la política entre la Revolución de Mayo y el rosismo (Buenos Aires: Prometeo, 2007); un análisis del valor performativo de las parroquias en relación a las dimensiones territoriales barriales, en Sofía Gastellu, «La Justicia de Paz en la ciudad de Buenos Aires. La dimensión territorial de una justicia de proximidad (1821-1854)», en Justicias situadas. Entre el Virreinato Rioplatense y la República Argentina (1776-1864), ed. Darío G. Barriera (La Plata: FaHCE-Universidad Nacional de La Plata, 2017). 
Muchos de los barrios son centenarios, otros han desaparecido ${ }^{8}$, no todos gozan de reconocimiento jurídico, y existen algunos que fueron determinados recientemente. Siempre existieron gran cantidad de denominaciones no oficiales de barrios, aunque en la actualidad oficialmente la ciudad se encuentra dividida en 48 barrios, que legalmente están definidos como unidades territoriales con características identitarias propias9. Las comunas de la ciudad de Buenos Aires son las unidades administrativas y suelen contener más de un barrio de la ciudad.

Una diferente posibilidad de conceptualización la recoge la literatura del siglo XX, que en general define al barrio en términos de oposición al centro ${ }^{10}$. James Scobie considera que los barrios surgen aproximadamente en torno al año 1910 con la expansión de la ciudad promovida por los tranvías, el ferrocarril y los remates, haciendo así una relación entre el barrio y el suburbio de la ciudad ${ }^{11}$. Una posición diferente es la de Adrián Gorelik, quien reconoce la expansión del centro hacia los suburbios para 1910, pero ubica la construcción del barrio entre las décadas del 20 y el 30, definiéndolo como una construcción social y cultural mucho más compleja que la definición jurisdiccional. Dicha

8 Algunos barrios en la actualidad no existen, varios de ellos fueron parroquias, jurisdicciones civiles de paz o sitios que tomaron denominaciones antiguas, relacionadas con espacios de culto, de sociabilidades urbanas, o relativos a las actividades económicas de sus pobladores. Entre ellos se encuentran el Bajo de Las Catalinas, Catalinas Norte, Catalinas Sur, Catedral al Sur (también denominado Barrio Sur), Catedral al Norte, El Alto de Lezama, El Barrio de Las Ranas, El Puerto de los Tachos, La Quema, Tierra del Fuego, La Siberia, Las Mil Casitas, Santa Lucía, Socorro, Tres Esquinas, Villa Mazzini, Villa Malcolm y Villa Talar. Ver para el caso del barrio Villa Manzini el capítulo 1 de Beatriz Sarlo, La máquina cultural. Maestras, traductores y vanguardistas (Buenos Aires: Siglo XXI, 2017). Para el caso de Catedral al Norte, Catedral al Sur, Socorro y Santa Lucía, ver Sofía Gastellu, "La Justicia de Paz en la ciudad de Buenos Aires".

9 Para finales de la década de 1960 surgió la necesidad de fijar los límites jurisdiccionales de los barrios de la ciudad de Buenos Aires, llevando a cabo una definición precisa de sus contornos. El proyecto de fijar estos contornos de forma precisa e invariable respondía a un proyecto de descentralización (fallido) de la administración de la ciudad, ideado durante el gobierno militar del general Onganía, que propició la sanción de las normas legales necesarias tomando como referencia a las sociedades de fomento. Así, en el año 1968 el entonces Concejo Deliberante de la Ciudad de Buenos Aires dictó la Ordenanza Municipal No. 23698 que señaló 46 barrios porteños. Posteriormente, a dicha ordenanza se le realizaron reiteradas modificaciones hasta llegar a los 48 barrios, con la inclusión de Parque Chas, cuyos límites fueron establecidos en el año 2006, cuando fue publicada en el Boletín Oficial la Ley 1907.

10 Una influencia clave es la perspectiva de Roberto Arlt, Aguafuertes porteñas (Buenos Aires: Losada, 1973).

11 Roberto Giunta, "Revolución industrial y barrio", en Buenos Aires. El libro del Barrio. Teorías y Definiciones, eds. Liliana Barela y Mario Sabugo (Buenos Aires: Instituto Histórico de la Ciudad de Buenos Aires, 2004), 107-122. 
postura es compartida por Luciano de Privitellio y está en sintonía con la de Leandro Gutiérrez y Luis A. Romero en lo que hace a la formación de las sociedades de fomentos en los barrios, que coinciden en ubicar al barrio en el período de entreguerras ${ }^{12}$. La diferenciación entre viejos y nuevos barrios es caracterizada como un proceso que influyó fuertemente en la transformación identitaria de los sectores populares urbanos durante dicho período. Los barrios tradicionales eran aquellos que rodeaban el denominado centro de la ciudad (San Telmo, Barracas, La Boca, San Cristóbal, Balvanera y el Norte) y la primera periferia que se visibilizaba hacia 1910 estaba constituida por Almagro, Caballito, Flores, Belgrano, el bajo Belgrano, Palermo o Villa Crespo ${ }^{13}$.

Podemos considerar al barrio como una subdivisión con identidad propia de una ciudad. Su origen puede ser una decisión, una iniciativa o meramente un sentido común de pertenencia de sus habitantes basado en la proximidad o historia, y muchas veces reforzado por el antagonismo con otro barrio contiguo ${ }^{14}$. En estas definiciones ya se ven las tensiones entre una lógica administrativa, una comunal y otra que podemos definir como de proyección urbanística o empresarial. Aquí nos centraremos en la definición de la lógica comunal, que hace referencia a las identidades construidas en torno a un espacio definido políticamente, o lo que para nosotros serán identidades territorializadas ${ }^{15}$. Indagaremos una posible relación con las UUPP que se asentaron en dichos barrios, especialmente las que se instalaron en la zona sur de la ciudad de Buenos Aires,

12 Adrián Gorelik, La grilla y el parque. Espacio público y cultura urbana en Buenos Aires 1887-1936 (Buenos Aires: Universidad de Quilmes, 1998); L. A. Romero y L. Gutiérrez, Sectores populares, cultura y política. Buenos Aires en la entreguerras (Buenos Aires: Sudamericana, 1995); De Privitellio, Vecinos y ciudadanos. Política y sociedad en la Buenos Aires de entreguerras.

13 Ricardo González Leandri, "La nueva identidad de los sectores populares", en Crisis económica, avance del Estado e incertidumbre política (1930-1943), ed. Alejandro Cataruzza, Vol. VII, Nueva Historia Argentina (Barcelona: Sudamericana, 2011), 213-14.

14 "Esto es el barrio porteño, barrio profundamente nuestro; barrio que todos, reos o inteligentes, llevamos metido en el tuétano como una brujería de encanto que no muere, que no morirá jamás". Roberto Arlt, Aguafuertes porteñas, 16.

15 Aquí remito a la distinción entre espacio y territorio, considerando el primero una extensión organizada a partir de criterios no solamente políticos, sino económicos, culturales, religiosos, administrativos; a diferencia de un territorio, que se constituye mediante una acción política sobre la tierra y sus habitantes. Ver Darío G. Barriera, Abrir puertas a la tierra. Microanálisis de la construcción de un espacio político. Santa Fe, 1573-1640 (Santa Fe: Museo Histórico Provincial Brigadier Estanislao López, 2013), 38. 
constituyendo para el imaginario social porteño lo que puede ser identificado con el "Barrio Sur"16.

\section{Sur, / PAREdón y Después... / Sur, / UNA LUZ de ALMACÉn... ${ }^{17}$}

Podemos considerar a la Avenida de Mayo, construida en 1894, como la línea divisoria de la ciudad de Buenos Aires, trazando un norte y un sur de una ciudad dividida en un ala más rica y otra más pobre, una más nueva y otra más vieja ${ }^{18}$. Una visión caracteriza el eje sudoeste, vertebrado por el Riachuelo, como una clave de la conformación del área industrial metropolitana ${ }^{19}$. Según James Scobie, los distritos del sur quedaban muy relegados en materia de servicios, instalaciones y oportunidades. La ciudad presenta grandes diferencias entre el norte y el sur, que aún perviven. Quizás porque desde la geografía el sur fue zona de bañados, arroyos, camino de la basura, puerta de atrás de la ciudad, haciendo que estas sucesivas formas de ocupación del espacio determinaran que la zona sur se identificara con los sectores más vulnerables de la población ${ }^{20}$.

La zona sur aparece en diversos testimonios como una frontera con respecto al resto de la ciudad, o mejor dicho, con respecto a los mejores sitios de la ciudad con los que se le suele comparar. Por lo tanto, el sur es vivido como un sitio postergado por todos los gobiernos en el momento de su equipamiento y como un gran lugar de arribo, pero también como

16 Entendemos el imaginario social a partir del concepto desarrollado por Sergei Moscovici de representación social, ya que ambos conceptos guardan una gran similitud y en este caso pueden funcionar como términos intercambiables. Dichos conceptos refieren a la existencia de un esquema interpretativo de la realidad socialmente legitimado, que contiene manifestaciones materiales en tanto discursos, símbolos, actitudes, valoraciones afectivas y conocimientos legitimados históricamente y por tanto modificables. Funcionan como matrices tanto para la cohesión como para la identidad social y suelen ser difundidos a través de la escuela y los medios de comunicación, teniendo un alto grado de compromiso con los intereses de los grupos hegemónicos. Para mayor profundidad del concepto consultar José Antonio Castorina (coord.), Construcción conceptual y representaciones sociales. El conocimiento de la sociedad (Buenos Aires: Miño y Dávila, 2005).

17 Aníbal Troilo (música) y Homero Manzi (letra), Sur (Tango), 1948, http://www.todotango.com/ musica/tema/372/Sur/ [fecha de consulta: 23 de febrero 2019].

18 Francis Korn, Los huéspedes del 20 (Buenos Aires: Sudamericana, 1974).

19 Adrián Gorelik y Graciela Silvestri, "Imágenes al sur. Sobre algunas hipótesis de James Scobie para el desarrollo de Buenos Aires", Anales del Instituto de Arte Americano e Investigaciones Estéticas «Mario J. Buschiazzo». FADU-UBA, No. 27-28 (1991).

20 James Scobie, Buenos Aires. Del centro a los barrios, 1870-1910 (Buenos Aires: Solar, 1977); Adrián Gorelik y Graciela Silvestri, "Imágenes al sur"; Graciela Silvestri, El color del río. Historia cultural del paisaje del Riachuelo (Bernal: Universidad Nacional de Quilmes-Prometeo, 2012). 
punto de partida, donde sus pobladores fueron expulsados o se trasladaron. De esta forma, es el resultado de una enorme diversidad y, aún más, es el ámbito superador de divisiones, donde confluyen identidades en constante tensión, calidoscopio siempre en movimiento, aunque sin dejar de lado su esencia popular. Un calidoscopio por el que desfilan imágenes de las principales luchas obreras y de la vida cotidiana de los sectores medios porteños, con su esplendor y su caída ${ }^{21}$.

Ricardo Lopa construye la noción de Barrio Sur de acuerdo a su "porteña subjetividad", "el mismo es comprensivo de Boedo, Patricios y Pompeya, [su] mi cuna, arrabal"22. En este trabajo extenderemos dichas fronteras comprendiendo también a La Boca y a Barracas, pero mantendremos la convicción de que todo límite barrial responde a una carga subjetiva significativa, en sintonía con lo que también afirmara Rodolfo Kusch, quien comprende como barrio "esas cuatro cuadras que uno siempre recorre, con algunas verjas y casas típicas y con las cosas que juntamos, esas que son sagradas pa'mí, que mantienen el nexo y el sentido de mi vida [...]"23.

\section{La Universidad Popular de la República de La Boca}

De Soiza Reilly se refiere al barrio de La Boca como la República Genovesa, debido al origen de la mayoría de sus pobladores. Debe mencionarse que, entre mítico e histórico, el origen de esta república barrial suele decirse que está en el intento de independencia de los genoveses a fines del siglo XIX ${ }^{24}$. De este primer intento separatista los registros más antiguos los hallamos en una nota de la revista Caras y Caretas de 1904, firmada por Blas Vidal e intitulada "La República de La Boca. Los Carbonarios - La Vendetta - La Maffia - La Mano Negra”.

21 Daniel Paredes et al. (comps.), Buenos Aires, voces al sur. Construcción de identidades barriales (Buenos Aires: Instituto Histórico de la Ciudad de Buenos Aires, 2006).

22 Ricardo Lopa, Sur. Barrio de tango, amor y revolución (Buenos Aires: Agebe, 2014), 5.

23 Rodolfo Kusch, Obras completas (Buenos Aires: Fundación Ross, 2007), 376-77.

24 Para profundizar en el conocimiento de la historia de las tres repúblicas boquenses consúltese: Rubén Granara Insúa, La República de La Boca (Buenos Aires: Ed. La Boca del Riachuelo, 1986); "Cuando la República de La Boca se independizó", Diario Popular, Buenos Aires, 9 de febrero de 2017, https://www.diariopopular.com.ar/barracas-la-boca/cuando-la-republica-la-boca-se-independizo-n300656 [fecha de consulta: 16 de octubre de 2018]; "Un país disimulado al lado del Riachuelo", Diario La Nación, Buenos Aires, 13 de diciembre de 2006, https://www.lanacion.com. ar/867005-un-pais-disimulado-al-lado-del-riachuelo [fecha de consulta: 16 de octubre de 2018]. 
Allí el periodista detalla que en aquel barrio de ambiente "agenovesado" uno podía sentirse extranjero, ya que más que un barrio de la capital parecía tratarse de un territorio extraño, que expresaba un odio visceral a todo lo que fuera "del centro", arrojándole piedras y proyectiles diversos a todos los que tuvieran un carácter foráneo. En aquel barrio:

“intentaban allá por el año [18]76 la defensa política del barrio, organizando un «Comité de defensa» para solicitar al gobierno central la autonomía de la Boca, que dependía municipalmente del Consejo Deliberante, y políticamente, para los efectos electorales, de la parroquia de San Telmo, que es precisamente lo que en ningún caso admitían ellos; ni querían entenderse con la municipalidad central, ni querían depositar sus votos en las urnas del atrio de la calle Comercio. Y razones tenían para ello, pues desde la primera vez que, capitaneados por don Sebastián Casares en el año 63, fueron à votar allí, no se dio el caso de que salieran con bien de ninguna elección; las puñaladas estaban a la orden del día y rara era la vez que volvían todos los boquenses que vinieron á San Telmo [...] al haberse inmiscuido algunos vecinos italianos que hicieron serios trabajos para encauzar en otro sentido aquel movimiento separatista, deseosos de que la Boca fuera algo así como una sucursal de la bella Italia en pleno Río de la Plata. Proyectaron estos [...] la nueva república que á no dudarlo rivalizaría con sus hermanas de Mónaco, San Marino y Andorra [...] Pero todas esas alzadas insurrectas quedaron luego en lo que debían quedar; ni aquellos consiguieron la autonomía, ni lograron estos ver cumplida su intentona republicana [...] de todo aquello solamente le quedó á ese rincón de Buenos Aires, simpático por muchos conceptos, el bautismo de republicano que le procuraron sus improvisados padrinos" 25 .

En la actualidad La Boca ya ha contado con tres "repúblicas", las dos últimas de carácter humorístico y sin la violencia que caracterizó al periodo anterior: desde la postura independentista formal de los genoveses, perdida en los albores de la historia y confundible con lo mítico, las repúblicas en clave de sátira se crearon como espacios de socialización, ocio y solidaridad vecinal. Si bien estas "Repúblicas

25 Blas Vidal, "La República de la Boca. Los Carbonarios - La Vendetta - La Maffia- La Mano Negra", Caras y Caretas, Buenos Aires, 4 de septiembre de 1904, 40-41. 
irreverentes" - la Segunda República de La Boca contó por ejemplo con un Emperador de la Fugazza con Queso ${ }^{26}$ - parecen ser un caso excepcional de la ciudad de Buenos Aires, encontramos en Francia cierta sintonía con la creación de la Comuna Libre de Montmartre ${ }^{27}$, tanto en el carácter irreverente como en el vínculo que estas comunas o repúblicas entablaron con los artistas y distintos miembros de la comunidad local -el pintor Benito Quinquela Martin es el paradigma del vínculo artístico para el caso boquense $-{ }^{28}$.

Para de Soiza Reilly el barrio mantiene una especie de simbiosis sincrónica entre su desarrollo y el del país, ya que:

"La Boca del Riachuelo no es solamente, como muchos suponen, un rincón pintoresco para la literatura de los tangos. Es, sobre todo, el barrio donde mayor puede medirse la fuerza del país. La vida entera de la República se ausculta, fácilmente, en la respiración de sus planchadas, en el trajín de sus hormigas, en el trabajo de sus guinches, en la inquietud febril de sus camiones cargados de productos. No es posible concebir la vitalidad, la multiplicación, la electricidad del país, si no se ha visto alguna vez la Boca del Riachuelo. De día, al obscurecer o por la madrugada -en invierno o verano- las calles, las avenidas, las dársenas, los cafetines, los bodegones, las tiendas, los almacenes, las barracas, palpitan y reflejan los diferentes estados de salud, las crisis, las prosperidades, las bancarrotas, los triunfos de nuestro territorio. La Boca parece la boca del mundo" 29 .

El historiador Antonio J. Bucich describe cómo un 2 de junio de 1917 se concretó la fundación de la Universidad Popular en el local del Comité Radical del Barrio de La Boca:

26 La fugazza con queso es una pizza típica de Argentina, que consta de la tradicional masa de pizza, cebolla y mozzarella. Se considera que fue creación de Juan Banchero, un inmigrante italiano que se instaló en el barrio de La Boca. Ver Horacio Spinetto, Pizzerías de valor patrimonial de Buenos Aires (Buenos Aires: Dirección General de Patrimonio e Instituto Histórico, 2008), 118.

27 Véase «La Comuna Libre de Montmartre», http://www.montmartre-guide.com/es/historias_ montmartre/la-comuna-libre-de-montmartre/ [fecha de consulta: 16 de octubre de 2018].

28 Durante la Segunda República de La Boca el pintor ocupó el cargo de Gran Almirante dentro del Consejo Supremo.

29 Juan José de Soiza Reilly, "Viaje a través de los barrios de Buenos Aires. La República Genovesa de La Boca”, Caras y Caretas, Buenos Aires, 18 de octubre de 1930, 7. 
"surgió la idea de fundar un centro docente dedicado principalmente a los trabajadores. Un año antes había acicateado al doctor Anastasi alguna inquietud de este género. El joven universitario, que después de haber oteado los horizontes de su tiempo por incorporarse al radicalismo, maestro de escuela, quiso llevar al seno de la entidad política en que actuaba, los gérmenes de sus nobles inquietudes. Primitivamente se había pensado en echar los cimientos de una Academia de estudios sociales y políticos. Pero su aproximación al doctor Le Breton -que por esa época actuaba con sentido práctico atento a las aspiraciones y a las necesidades del pueblo- cambió ese primer enfoque. El doctor Anastasi vio que era mejor este campo de labor cultural, la enseñanza con un sentido netamente constructivo, capaz de dotar a los obreros manuales y a los noveles estudiantes de instrumentos eficaces para su desenvolvimiento en la vida de relación. A ese establecimiento que se esbozó en las reuniones efectuadas en el comité radical de la 4ta. Circunscripción, se dejó bien sentado desde un comienzo, "tendrían acceso todos los que deseen, sin distinción de creencias políticas (...)”30.

\section{Imagen No. 1}

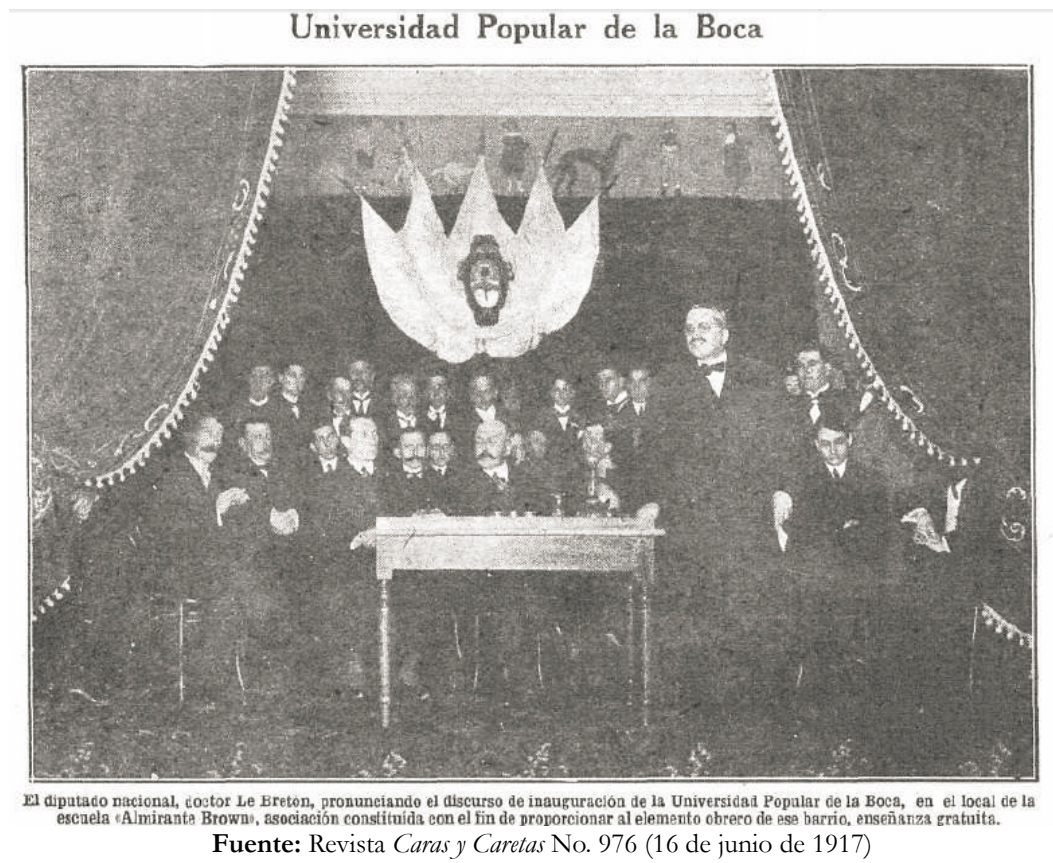

30 Antonio J. Bucich, Ubicación boquense del Dr. Tomás A. Le Bretón. Cuadernos de la Boca del Riachuelo, 25 (Buenos Aires: Escuela de Artes Gráficas, 1967). 
La trayectoria pública de Tomás Le Bretón, así como las de otros miembros notables y jóvenes promisorios del Partido Radical, fueron provechosas para el fundador de la Universidad Popular de La Boca (UPdLB), dotando de una impronta particular a dicha institución por su bagaje ideológico y organizativo. Tomás Le Bretón tuvo una destacada vida política: participó de la fundación de la Unión Cívica de la Juventud, de la Unión Cívica Radical (UCR) ${ }^{31}$ y de la Unión Cívica Radical Antipersonalista, y durante el período 1912-1928 desempeñó diversos cargos públicos, siendo Diputado y Senador por la Ciudad de Buenos Aires. También durante un breve tiempo - en la presidencia de Alvear- fue Ministro de Agricultura ${ }^{32}$. La Junta Directiva de la UPdLB estaba casi en su totalidad compuesta por miembros de la UCR -de posterior adscripción a la facción antipersonalista de la UCR-; entre ellos destacaron Ángel Gallardo (vicepresidente de la UPdLB), Arturo Goyeneche (vicepresidente segundo), Benjamín Bonifacio (secretario de la comisión directiva) y Leónidas Anastasi (tesorero). Ángel Gallardo fue presidente del Consejo Nacional de Educación (19161921) y Ministro de Relaciones Exteriores y Culto (1922-1928); el

31 La Unión Cívica Radical (UCR) es uno de los dos partidos políticos actualmente activos más antiguos de la Argentina y el segundo en caudal electoral. Fue fundado en 1891 por Leandro N. Alem tras la Revolución de 1890 y el rompimiento con otros sectores que habían conformado La Unión Cívica. Con más de cien años de existencia, el Partido Radical tuvo diferentes conformaciones y fracturas. Gobernó en nueve oportunidades el país. Hipólito Yrigoyen fue el primer presidente representante de este partido. Esto se hizo posible tras la sanción de la Ley Saenz Peña, que en 1912 reglamentó el voto universal, secreto y obligatorio para varones mayores de 21 años, y que auspició que el Partido Radical abandonara su política de abstención electoral y concurriera a los comicios. Este periodo es denominado por algunos autores como de democracia ampliada. Finalizada la presidencia de Yrigoyen le sucedió otro radical, Marcelo T. de Alvear, quien para la historiografía más tradicional desarrolló una presidencia marcadamente diferente a la de su antecesor, de tintes más aristocráticos, si bien se considera que este partido jamás dejó de ser representativo de los nuevos sectores medios. Puede consultarse: Marcela Ferrari, Los políticos en la República Radical. Prácticas políticas y construcción de poder (Buenos Aires: Siglo XXI, 2008); Ana Virginia Persello, El partido radical. Gobierno y oposición, 1916-1943 (Buenos Aires: Siglo XXI, 2004); David Rock, El Radicalismo Argentino. 1890-1930 (Buenos Aires: Amorrortu, 2010).

32 Hemos intentado desarrollar un abordaje prosopográfico más exhaustivo para el caso de la UPdLB en trabajos previos. Consúltese Alejandro Martín Yaverovski, «Tomás Le Bretón: ¿exponente de una propuesta educativa alvearista?» (Ponencia presentada a las XVI Jornadas Interescuelas/Departamentos de Historia. Mesa 59: «Teoría e Historia de la Educación Popular en Latinoamérica y América del Norte, siglos XIX y XX», Universidad Nacional de Mar del Plata, 2017); Alejandro Martín Yaverovski, «Los ingenieros agrónomos en los primeros años de la Universidad Popular de la Boca». (Ponencia presentada en el XIII Congreso Iberoamericano de Historia de la Educación Latinoamericana CIHELA, Montevideo, 2018). 
primer cargo lo ocupó durante las presidencias radicales de Yrigoyen y Alvear. Arturo Goyeneche llegó al cargo de Diputado Nacional y Presidente de la Cámara de Diputados por la UCR, como representante de la Capital Federal (1919- 1921); también fue Intendente de Capital Federal (1938-1940) durante la presidencia de Roberto M. Ortiz. Este último fue también colaborador de la UPdLB y tuvo una reconocida trayectoria dentro del radicalismo antipersonalista. Benjamín Bonifacio fue Diputado de la UCR por Capital Federal (1916-1919). Leónidas Anastasi, de presencia destacada en el barrio de La Boca, fue un reconocido abogado laboralista y partícipe de la política obrerista desarrollada por el presidente Yrigoyen y continuada por Alvear: en 1920 presidió la delegación argentina enviada a la conferencia de la Organización Internacional del Trabajo realizada en Washington; fue Diputado por la provincia de Buenos Aires (1920-1924) y Diputado por la Capital Federal (1938-1940). Otra personalidad dentro de la UCR fue uno de los vocales de la UPdLB, Honorio Pueyrredón, que se desempeñó también como Ministro de Agricultura (1916-1917), Ministro de Relaciones Exteriores y Culto (1917-1922) y Embajador de Argentina en Estados Unidos (1924-1928). También otro vocal de la UPdLB, Leopoldo Melo, se destacó como funcionario político de la UCR antipersonalista; fue senador por la provincia de Entre Ríos (1916-1930) y Ministro del Interior (1932-1936) ${ }^{33}$.

La UPdLB será tan relevante para la cultura barrial, que el cronista de Soiza Reilly, al describir la actividad cultural en La Boca, la incluirá del siguiente modo:

"Se creía que un barrio trabajador como La Boca carece de tiempo para su cultura. ¡Al contrario! Las escuelas hállanse repletas. Las asociaciones laicas, las congregaciones religiosas, los liberales, los católicos, los evangelistas de Mr. Morris, el Ejército de Salvación, los hebreos, todos los grupos y todas las sectas, poseen sus escuelas, sus salas de conferencias, sus bibliotecas públicas. Funciona una universidad, fundada por el doctor Tomás Le Breton, -"La Universidad de La Boca"- que

33 Los perfiles y trayectorias fueron relevados en base a diccionarios biográficos y a los datos suministrados por la Dirección de Archivo, Publicaciones y Museo de la Cámara de Diputados Nacionales. 
es una noble institución heroica. Con escasos recursos oficiales se da en ella instrucción técnica y científica a mil y pico de alumnos. Bajo la dirección del profesor Soler, la universidad marcha como un cronómetro. Los alumnos concurren de noche después de su trabajo. Son obreros de todas las edades desde los siete años hasta los ochenta [...]"34.

De acuerdo a una crónica aparecida el 9 de julio de 1917 en el periódico El Escolar. Órgano de la Asociación Infantil General Bartolomé Mitre, el día 2 de junio se inauguró la institución en el "precioso" local de la escuela Almirante Brown, ocasión en la que Leonidas Anastasi pronunció el siguiente discurso:

"No pediremos al estado más de lo que nos ha dado. El Consejo Nacional de Educación ha cedido este soberbio edificio y proporcionado abundante material de enseñanza. La Universidad se ha ubicado en este palacio como no soñábamos tenerlo. Recuerdo que el doctor Le Breton pedía un modestísimo local para instalarla. Le pasa lo que a las heroínas de los cuentos de hadas: se acostó en una choza y ha amanecido en un palacio" 35 .

Esta iniciativa contó de inmediato con el amplio apoyo de la localidad, ya que los centros sociales mercantiles y culturales le dieron presto apoyo. El Consejo Escolar IV -presidido entonces por el Dr. Carlos R. Vignale- gestionó y obtuvo del Consejo Nacional de Educación - que tenía como titular al doctor Ángel Gallardo- la autorización para disponer del local de la Escuela No. 1 de varones Almirante Brown, situada en la calle Aristóbulo del Valle $471^{36}$. Recién en 1964, después de activas gestiones ante la Municipalidad de la Ciudad de Buenos Aires, fue concedida a la Universidad Popular de La Boca (UPdLB) el solar que antiguamente ocupara el viejo Hospital Cosme Argerich en la calle Pinzón 546, actual predio que ocupa totalmente para sus actividades

34 Juan José de Soiza Reilly, "Viaje a través de los barrios de Buenos Aires. La República Genovesa de La Boca".

35 Citado en Universidad Popular de La Boca, 50 Aniversario. Universidad Popular de La Boca, 1917 - 2 de junio - 1967. Medio siglo dedicado a la educación del Pueblo (Buenos Aires: Talleres Gráficos el Triángulo, 1968), 8.

36 Universidad Popular de La Boca, 9. 
educativas, tras dejar de realizar actividades en la Escuela Almirante Brown $^{37}$.

La Revista de las Universidades Populares Argentinas ${ }^{38}$, más de veinte años después de la fundación de la institución boquense, reconocerá la coincidencia de los suyos con:

"[...] las finalidades que se propusieron Le Breton y Victorino Ortega, verdaderos apóstoles de un grande y significativo ideal de culturación popular [...] En todas estas organizaciones se procura enseñanza técnica y práctica, siguiendo el ritmo impuesto a las Universidades Populares de los E.E. U.U. de Norte América"39.

$\mathrm{Al}$ igual que los objetivos, en el transcurrir del tiempo el sujeto al cual están destinadas estas propuestas también se mostrará incólume: "Se orienta a la juventud hacia los estudios prácticos en forma ascendente, de acuerdo con la evolución industrial no solo de nuestro país sino de las naciones limítrofes" $"$.

En la mencionada publicación el reconocimiento a Le Bretón es constante; no falta nunca la oportunidad de conmemorar la efeméride de cada aniversario de la UPdLB. Por momentos las conmemoraciones

37 Universidad Popular de La Boca, 14.

38 Santiago Canop se refirió así a la Revista de las Universidades Populares Argentinas: "Las Universidades Populares Argentinas reflejan su vida en un órgano de publicidad, en su Revista, que dirige desde su fundación (año 1936) el consejero de las U.P.A., el doctor Benjamín E. del Castillo, que aparece mensualmente, y que tiene amplia difusión. Modesta en sus comienzos, la publicación contuvo al principio temas relacionados con los institutos en cuyo seno ve la luz. Pero luego, gracias al empeño puesto por sus colaboradores, la Revista ha ido ampliando paulatinamente la índole y el alcance de su contenido, fiel reflejo de cuanto acaece en las Universidades, contiene artículos y comentarios de actualidad. En algunos números aparecieron trabajos sumamente interesantes, que versaban sobre materias. Escritos por personas especializadas, resultan útiles para que el profano adquiera nociones sobre tópicos difíciles. Personas especializadas hemos dicho. En efecto, los autores han sido profesores de las diversas materias. Destacar algún artículo entre los citados, nos parecería fuera de lugar. Solo diremos, en general, que la finalidad que se propusieron los que dirigen la Revista, de convertirla en un medio de difusión de cultura, se ha cumplido plenamente". Santiago Canop, Obra y acción de las Universidades Populares Argentinas (Buenos Aires: Talleres Gráficos Macagno Hnos. \& Landa, 1941), 115.

39 Benjamín E. del Castillo, "La obra cultural de las U.P.A.”, Revista de las Universidades Populares Argentinas (febrero de 1940): 394.

40 Benjamín E. del Castillo, "La obra cultural de las U.P.A.”: 395. 
resultan lisonjeras en la forma en que se refieren al político argentino y sus allegados:

"Hablar del Dr. Le Breton, es hablar con lealtad de quien lanzó la chispa de la obra hoy consagrada de las Universidades Populares [...] Cuando en el año 1917, fundara la Universidad Popular de la Boca, que prosigue la obra que él inició, no se creyó que después de veinte años esta misma obra hubiera llegado a su total consagración. Diremos que Le Breton, como Diputado Senador y Ministro, nunca descuidó las necesidades de su pueblo, y se rodeó de hombres talentosos como Ángel Gallardo, Roberto M. Ortíz, Leonidas Anastasi, Arturo Goyeneche, José Antonio González y otros, para dar al país el ejemplo de que era necesaria una nueva educación para el obrero, levantando su nivel moral y dándole mejores medios para su defensa en la lucha por la vida. Se rodeó igualmente de jóvenes como Sebastián Soler, su primer Director, y con Profesores que aún hoy [1936] prosiguen colaborando con perfecto entusiasmo humano y patriótico en esta obra tan generosa como digna. Por eso Le Breton merecerá en su hora el homenaje grandioso que le debe este pueblo por su iniciativa en favor de la cultura pública"41.

La Revista de las Universidades Populares Argentinas rescata del siguiente modo la visita que realizara el pedagogo correntino José Alfredo Ferreyra a la Universidad del barrio de La Boca en 1933:

"Visité la Universidad de La Boca [...] La vi en pleno funcionamiento, y la impresión que me produjo fue digna del primer centro docente de su índole creado en la metrópoli. Funciona en la escuela "Aristóbulo del Valle", hermoso local [...] invitaba al trabajo a 700 jóvenes venidos voluntariamente no solo del barrio de La Boca, sino de todos los de la Capital, aún de los pueblos de la Provincia de Buenos Aires que la rodean.

Es un centro atrayente de cultura, acreditado por sus resultados [...] centenares de jóvenes encontraron en sus aulas lo que buscaban: obtener o aumentar sus conocimientos para realizar su vida.

41 Revista de las Universidades Populares Argentinas (septiembre de 1936): 370. 
Porque estos adolescentes, jóvenes y hasta algún hombre maduro, pintado en canas, trabajan en fábricas o en industrias colectivas o individuales y sienten necesidad de mejorar su arte, incitados por la mayor recompensa material y moral. Este estímulo es uno de los beneficios de los trabajos en común, la comparación de las recíprocas aptitudes. [...] Esta Escuela Popular fue un trasplante realizado por el Dr. Tomás Le Breton, después de compenetrarse, como Embajador argentino y compatriota de Sarmiento, del ambiente educador de los Estados Unidos. Encontró aquí hombres que lo secundaran, [...] el Dr. Arturo Goyeneche [...] la organizó y la administró con espíritu democrático. Contó para eso con la colaboración técnica del Profesor Soler [...] la Escuela Popular es la combinación del espíritu cívico con la habilidad técnica. Cuando más vigorosos son estos factores y mejor se combinan, es más perfecta la Escuela. [...] [Los estudiantes] escuchan, de veterinarios, agrónomos, ingenieros, electricistas, profesores de inglés o de contabilidad, personal experimentado que por saber de su materia elige lo más útil o interesante; lo que se presta a demostraciones, aplicaciones, adaptándose al temperamento y preparación de los estudiantes. Este es un tipo de verdadera escuela nueva que no corta la unidad y continuidad de la escuela argentina, la cual viene de lejos, como concepto, procedimientos y métodos" $"$.

\section{Imagen No. 2}

Curso de lechería del Profesor Ingeniero Agrónomo Arturo Pimentel.

Universidad Popular de La Boca, 1918.

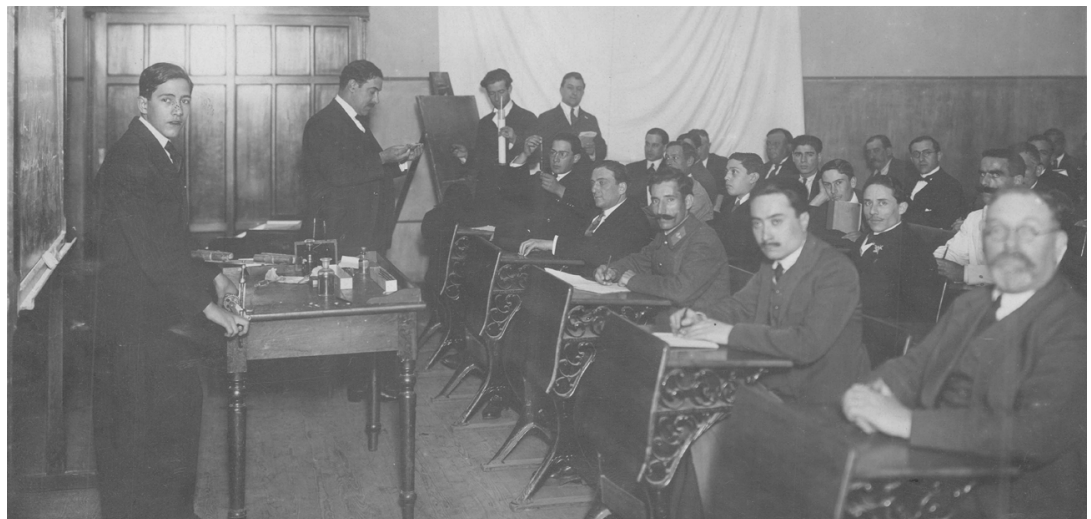

42 Revista de las Universidades Populares Argentinas (mayo de 1937): 443-446. 


\section{La Universidad Popular de la República de Boedo}

Qué cosa Boedo, única calle-barrio. Barrio por prepotencia de su cultura y personalidad. Era la alternativa a las luces del centro. Eran las luces de Boedo, de Independencia a Cochabamba $[\ldots]^{43}$.

En 1882 el antiguo municipio porteño llegaba hasta el arroyo Maldonado al norte, la actual calle Boedo al oeste y el Riachuelo al sur. La calle de la cual va a tomar el nombre el barrio es uno de los límites de la ciudad. Durante el siglo XIX pertenecía a la periferia del núcleo urbano, era una zona de quintas, tambos lecheros y hornos de ladrillos. A su vez, fue una importante vía de circulación hacia el "centro", el Riachuelo o el viejo Matadero del Parque de los Patricios. Desde principios del siglo XX la calle Boedo presenta una tradición de despachos de bebidas y cafés en los cuales se desarrolló una amplia sociabilidad que vinculaba prácticas culturales muy diversas, que se relacionaban con el tango, la literatura, el teatro, el fútbol y la política ${ }^{44}$. Así comienza un artículo publicado en la revista Atlántida en el año 1930:

"El pintoresco barrio de Boedo ha dejado de ser, hace ya mucho tiempo, aquel barrio de leyenda que en determinada época llegó a tener fama poco halagüeña. Hoy, Boedo ha progresado notablemente en todas las actividades, llegando a ser uno de los barrios más importantes de Buenos Aires" 45 .

La pujanza de un barrio en constante desarrollo sirve de escenario para la radicación de una Universidad Popular, la Universidad Popular de Boedo (UPdB), que funcionó en el local de la escuela elemental No. 8. Según el cronista anónimo, estaba "situada en el corazón de esa zona [y] es una consecuencia del rápido adelanto cultural de ese pedazo de ciudad".

45 "La Universidad Popular de Boedo", Atlántida (17 de julio de 1930): 23. 
Con el correr del tiempo, la zona semi-rural que rodeaba a la calle Boedo $^{46}$ se fue transformando. Era una importante vía de circulación, utilizada en las últimas décadas del siglo XIX por vehículos de tracción a sangre y por las tropillas de animales arriadas hacia el antiguo Matadero, que funcionó hasta el año 1900 en el cercano Parque de los Patricios, momento en el que fue trasladado al barrio de Mataderos. Llegaron además en aquellas décadas los tranvías a caballo y, ya entrado el siglo $\mathrm{XX}$, los primeros tranvías eléctricos. La red tranviaria constituyó uno de los factores de afincamiento de los primeros pobladores en diferentes barrios de Buenos Aires porque garantizaban a bajo costo las comunicaciones con los lugares de trabajo y con las áreas centrales de la ciudad.

El proceso de crecimiento apuntado tuvo particulares características en la barriada conformada en el entorno de nuestra calle Boedo. De Soiza Reilly se refiere en una de sus crónicas al barrio de Boedo como un barrio que es un poquito gaucho y un poquito doctor:

"De todas las repúblicas porteñas, Boedo es la más fecunda en escritores, en artistas, en músicos de ingenio. $\mathrm{Al}$ margen de la vida inquieta y callejera -vida jugadora de fútbol y agiotista- es fácil descubrir en Boedo otra vida más alta, más serena, más pura. Se advierte un afán de aprender; un gozo de estudiar; una sed de construir. Se ha levantado con tal fin la Universidad de Boedo, magnífica institución de cultura integral que preside el brillante escritor José González Castillo. Asisten todas las noches a sus aulas mil doscientos alumnos. Son obreros, son niñas, son muchachos. Se les instruye gratis con un cuerpo de profesores y técnicos que trabajan también gratuitamente. Además, cuenta Boedo con un conjunto de escritores y artistas nativos de noble prestigio. ¡Cosa extraña! Todos ellos conservan en sus obras la huella del ambiente. El espíritu criollo, triste, inquieto, arisco, febril pendenciero inocente e iconoclasta de Boedo -aire de la calle- se ha metido en sus producciones hasta el punto que esos artistas de la pluma, del

46 Nótese que en sus albores el barrio de Boedo, antes de tener su reconocimiento municipal como tal, era una calle que constituía una de las arterias más importantes del barrio de Almagro. Es más, por eso no es de extrañar que Ricardo M. Llanes indique que "En los anales de la docencia de Almagro, figura en la admirable empresa constructiva del poeta César Garrigós, la fundación de la Universidad Popular de Boedo (...)". Ricardo M. Llanes, El barrio de Almagro (Buenos Aires: Municipalidad de la Ciudad de Buenos Aires, 1968. Cuadernos de Buenos Aires, Vol. XXVI). 
cincel y del pincel han creado un estilo propio, característico. Es un estilo estético nativo:

-El estilo Boedo"

[el estilo de la] República de Boedo!

"capital del arrabal" -nos dice el tango Famoso de Julio de Caro.

En realidad, los escritores y artistas de Boedo forman una república que los defiende y los ampara"47.

En esta república de escritores ellos impulsaron la fundación de la UPdB, también conocida como la "Post Escuela", el 12 de febrero de 1928, en la sala del cine Los Andes. El acta fundacional tiene la firma de 74 personas y muestra la designación del primer Consejo Directivo, que tuvo como presidente a D. José González Castillo, con quién colaboraron el Dr. Julio Cruciani ${ }^{48}$ y Juan M. Lilla como vicepresidentes, y el Señor César Garrigós como secretario. El acto inaugural se cumplió el sábado 4 de agosto de ese mismo año en el cine Los Andes. La UPdB fue la segunda de tal tipo en constituirse en Buenos Aires, siguiendo el ejemplo de la UPdLB, creada en $1917^{49}$.

José González Castillo, su principal promotor y cuyo deceso sintió de forma notable la Universidad Popular ${ }^{50}$, fue uno de los máximos escri-

47 Juan José de Soiza Reilly, "Viaje a través de los barrios Porteños. La República de Boedo", Caras y Caretas, Buenos Aires, 11 de octubre de 1930, 6.

48 Julio Cruciani (1898-1949) fue un brillante clínico, especialista en alergia, creador del primer servicio en el Hospital Ramos Mejía, del que fue nombrado jefe por concurso, en 1940. También tenía un profundo interés por la cultura. Con González Castillo fundó la UPdB y la Peña Pacha Camac, y colaboró en la fundación del Teatro Libre Florencio Sánchez. Integró la Junta capitalina del Partido Socialista, del cual era militante activo. Las puertas de su casa permanecían abiertas día y noche para los casos urgentes. En Vicente Cutolo, Historia de los barrios de Buenos Aires (Buenos Aires: Elche, 1998), 265.

49 Desarrollamos una posible tipología de las Universidades Populares en Alejandro Martín Yaverovski, "Francia, Brasil, México y Argentina. Una propuesta de historia comparada para las Universidades Populares decimonónicas", en Eje: Problemas filosóficos, históricos y epistemológicos en educación. VI Jornadas Nacionales y IV Latinoamericanas de Investigadores/as en Formación en Educación (Buenos Aires: Instituto de Investigaciones en Ciencias de la Educación, Universidad de Buenos Aires, 2018). En diferentes fuentes consultadas se menciona reiteradamente a la Universidad Popular de La Boca como la primera Universidad Popular en Argentina, pero hemos encontrado evidencias de instituciones con la denominación de Universidad Popular previas a la fundación de la de La Boca. Por otro lado, la afirmación de que la Universidad Popular de Boedo fuese la segunda Universidad en crearse puede ponerse también en duda, dado que en una nota de la revista Caras y Caretas encontramos registro de las actividades de la Universidad Popular Bernardo de Irigoyen para el 8 de septiembre de 1917.

50 "Testigo y partícipe feliz de esos hechos [se refiere al X aniversario de la UPdB], fue Don José 
tores de las primeras décadas del siglo pasado. Afincado en Boedo, rápidamente se constituyó en la figura más relevante del barrio, al que entregó lo mejor de su pasión por el desarrollo cultural de la ciudad. Además de ser autor de innumerables obras de teatro y exitoso compositor de letras de tango, y de crear la UPdB, fundó en 1932 la Peña Pacha Camac $^{51}$. En un reportaje de la revista Atlántida González Castillo dejó explicitados los objetivos de la Universidad del Barrio de Boedo:

"Nosotros trabajamos por una escuela activa que rechaza la rigidez
alambicada de los programas y de los métodos y que fundamenta la
instrucción en el ejercicio libre y gradual de todas las facultades del
alumno, su intuición noble e intelectual aplicadas a los objetos de la
enseñanza en el orden natural. Formar hombres útiles y prácticos,
capaces de bastarse a sí mismos y de servir eficazmente a la sociedad" 52 .

En una entrevista su hijo Cátulo Castillo relata del siguiente modo la fundación de la Universidad efectuada por su padre y las características de los cursos que se impartían:

"En Boedo mi padre fundó la Universidad Popular. En ella enseñaba inglés, que sabía muy mal, pues lo había aprendido en Chile, durante el exilio, cuando trabajaba como corredor de vinos y debía ofrecer su mercadería a los comerciantes ingleses. Lo hablaba muy mal, pero lo enseñaba lo mismo. Su pasión por llevar las cosas adelante lo hacía vencer cualquier obstáculo",53.

González Castillo, fundador y primer Presidente de la Universidad, cuya desaparición tenemos ahora que lamentar. Entre los muchos frutos de su vida honrada, de su múltiple acción y de su fecunda inteligencia, esta UPdB -donde su nombre atrae todos los afectos- es auténtica expresión de sus afanes, prodigados con amplitud y ejecutados con esa magnífica holgura espiritual que lo caracterizó. Queremos con esta mención tributar un sincero homenaje a su memoria". Universidad Popular de Boedo. La «Post Escuela», Memoria del Ejercicio 1937 (Buenos Aires: Universidad Popular de Boedo, 1937), 5.

51 Aníbal Lomba, Boedo. Un barrio con historias (Buenos Aires: Ministerio de Cultura. Gobierno de la Ciudad de Buenos Aires, Comisión para la Preservación del Patrimonio Histórico Cultural de la Ciudad de Buenos Aires, 2006), 24.

52 "La Universidad Popular de Boedo", Atlántida (17 de julio de 1930): 23.

53 "Seis Poetas del Tango. Cátulo Castillo", La Maga, edición especial de colección, No. 16 (diciembre de 1995): 13. 
En la misma entrevista presenta un panorama sobre el barrio y la cultura reiterado en varias fuentes

"Boedo tenía vida propia y servía además con su tradición cultural a otros barrios vecinos. La llamada "cultura de Boedo" era un gran polo de atracción. La Universidad fue visitada hasta por don Marcelo T. de Alvear. Su período más brillante fueron los años que van del 20 al 30. Después comenzó a languidecer, aunque no han desaparecido sus ecos" ${ }^{\prime 4}$.

Cátulo Castillo también nos alumbra un poco sobre la red de vínculos que permitieron el sostenimiento y expansión de este tipo de propuestas educativas, cuando en la entrevista ya citada comenta sobre la creación de la República de Boedo y la acción de su padre:

"a través de Crítica nació a «La República de Boedo» de la que fue presidente mi padre, así también la «República de la Boca», que tenía como inspirador a Benito Quinquela Martin [...]. Y hasta fomentó artificialmente un antagonismo entre ambas «repúblicas»" $" 55$.

Posiblemente dicha rivalidad artificial fuera fomentada, en los medios de comunicación masivos de la época, con la finalidad de activar una competencia agonal que posibilitara cimentar la identidad y el orgullo de pertenencia al barrio, como también la participación activa en las distintas iniciativas de la sociedad civil, ya sea por el ingenio y la creatividad propia de los vecinos del barrio, o por la imitación de las iniciativas impulsadas por el "barrio rival".

En sus comienzos el plan de estudios de la UPdB constaba de las siguientes materias: Inglés, Francés, Castellano, Contabilidad, Taquigrafía, Dibujo Ornamental y Arquitectónico, Geografía Económica y Arte Escénico. La enseñanza era gratuita y las materias estaban dictadas por excelentes docentes y profesionales. Debido al éxito de la iniciativa y la enorme concurrencia de interesados, cuyo número llegó a 700 en

54 "Seis Poetas del Tango. Cátulo Castillo": 13.

55 "Seis Poetas del Tango. Cátulo Castillo": 13. 
unos pocos días, la inscripción de los alumnos tuvo que cerrarse mucho antes del término establecido. El número de alumnos inscriptos en su primer año llegó a 1287, entre ellos 436 mujeres.

Para su inauguración, estuvieron presentes los representantes del Consejo Nacional de Educación, el Secretario de la Intendencia, los Presidentes de ambas Cámaras Legislativas, Dres. Elpidio González y Andrés Ferreira, autoridades escolares, profesores y alumnos de la UPdB. En su discurso inaugural César Garrigós, Secretario General de la Universidad, habló sobre las características sociales de Boedo y el porqué de una institución como esa Universidad, y explicó a las autoridades oficiales y a los alumnos presentes que

"Con ello, queremos demostrar que no solo se hace obra patriótica con bellas frases conmemorativas y jugando con el nombre de nuestros antepasados, sino también queremos demostrar que se hace patria por medio de obras populares, democráticas, constructivas, es decir con hechos positivos y no con hermosas frases, porque los hechos como los nuestros son los que en realidad contribuyen a afirmar el amor a la patria, el respeto a nuestros mayores, y porque así es como se trabaja por el pueblo y se contribuye a la grandeza nacional. Con ello no queremos decir que estamos en contra de la pedagogía, ni de la docencia, ni del profesionalismo más o menos letrado de nuestros días, porque consideramos que ellos son los verdaderos culpables de haber creado entre nuestras orientaciones culturales una ridícula aristocracia del pensamiento, los peligros de la burocracia, el privilegio de la educación, la oligarquía de las minorías intelectuales y de haber contribuido a formar en nuestros últimos cuarenta años una tendencia académica verbalista, vana y presuntuosa que es una vergüenza para la cultura nacional”,56.

En una nota del año 1928 en el diario Crítica se detalla que las actividades de la UPdB estaban abiertas, ya que

56 Archivo de la Junta de Altos Estudios Históricos de Boedo, citado en Mónica Villa, José González Castillo. Militante de lo popular (Buenos Aires: Corregidor, 2015), 155-56. 
"todo ciudadano adulto sin distinción de nacionalidad, religión ni credo político podrá inscribirse y aprender lo que desee o necesite aprender, dentro del programa establecido, para adquirir conocimientos o para completar los que ya posee, de carácter práctico y en forma racional, que aumenten o perfeccionen sus medios de defensa en la lucha por la vida, esta enseñanza será absolutamente gratuita y estará a cargo de profesionales y técnicos especializados" ${ }^{\prime 7}$.

En las memorias que publicara anualmente la UPdB también queda registro de las objetivos y actividades que realizaba esta institución en dicho barrio:

"Fomentando en nuestro Establecimiento la educación intelectual como factor de equilibrio de la educación moral; en ambos casos hemos aplicado un criterio apropiado para seleccionar los sistemas de enseñanza, como asimismo las materias a desarrollar, experimentos no terminados aún y que continuaremos hasta alcanzar el perfeccionamiento necesario para ajustar su uso en beneficio de la masa que carece de orientación y que en sus horas libres de trabajo busca la perspectiva de adquirir nuevos conocimientos para mejorar su nivel de vida"58.

Con un tono casi propagandístico, en la misma memoria, correspondiente al año 1940, se menciona que, al cumplir su décimo cuarto año de existencia, la UPdB

"se encuentra colocada entre los primeros establecimientos de puertas abiertas o Universidades Populares del país; la sola mención del funcionamiento regular de sus 34 cursos de especialización y la concurrencia de 15.768 alumnos hasta el corriente año, demuestra terminantemente el valor de la enseñanza de características especiales que se imparte"59.

57 Crítica, Buenos Aires, 16 de julio de 1928, citado en Malena La Rocca, "Las prácticas de la cultura y educación popular: la lucha por la ocupación de espacios sociales", en Trabajadores y Educación en Argentina. De las estrategias sindicales a la acción de los movimientos sociales, comp. Roberto Elisalde, Marina Ampudia, Juan Pablo Nardulli y Joaquín Calvagno (Buenos Aires: Ed. Buenos Libros, 2011), 188.

58 Universidad Popular de Boedo. La «Post Escuela», Memoria del Ejercicio 1940 (Buenos Aires: Universidad Popular de Boedo, 1941), 5.

59 Universidad Popular de Boedo. La «Post Escuela», Memoria del Ejercicio 1940, 5. 
Más adelante, postula la causa del éxito de la institución: "Podemos afirmar rotundamente que el arraigo de la Institución es definitiva, habiendo trascendido la eficacia de su enseñanza y su buena organización, ya que concurre un buen número de alumnos de otras zonas, algunas de ellas bien alejadas de Boedo"60.

Cabe mencionar que desde principios del siglo XX comenzaron a funcionar las Sociedades Populares de Educación, cuya actividad estaba destinada a complementar la instrucción pública, ya que absorbían a los sectores de la población desatendidos por el sistema escolar (mujeres, obreros, desertores escolares, discapacitados). Pero aun cuando en el movimiento de Sociedades Populares se discutía quién se debía hacer cargo de la capacitación laboral, no se consideró tal tema como su finalidad principal, dando lugar solo a la enseñanza de algunos oficios ${ }^{61}$.

La UPdB llegó a contar con una matrícula anual que superaba los 1500 alumnos, dándose las clases en horarios vespertinos en las aulas de la Escuela No. 2, Boedo 650. En 1943, al producirse el desalojo de la escuela Patricias Argentinas, que funcionaba en un local alquilado en Av. San Juan y Colombres, los alumnos que concurrían a la misma fueron derivados a la escuela Gurruchaga, desalojando de ese lugar a la UPdB. En realidad, se trataba ya de la avanzada que el gobierno militar de entonces, surgido de la revolución de 1943, realizaba sobre las instituciones de este tipo. La actividad de la UPdB fue lentamente decayendo, al negársele los fondos de subsidio que recibía regularmente para parte de su sostenimiento administrativo.

A mediados de abril de 1943, con un despliegue extraordinario de fuerzas policiales, los profesores y alumnos de la Universidad fueron obligados a dejar las aulas. Esto manifiesta cierta sintonía con la política estatal que comienza a desplegarse en los años 1930, cuando ya desde los gobiernos de Uriburu y Justo se inició la tendencia a la atención estatal de la capacitación técnico-profesional, aunque dominaron los

60 Universidad Popular de Boedo. La «Post Escuela», Memoria del Ejercicio 1940, 8.

61 Adriana Puiggrós (comp.), Historia de la Educación en la Argentina. Vol. II: La educación argentina desde la Reforma Saavedra Lamas hasta el fin de la década infame (Buenos Aires: Galerna, 2000), 57-58. 
elementos espiritualistas y culturalistas y la preocupación por el nacionalismo, y se comenzó a hostigar a este tipo de experiencias. En algún momento un funcionario ofreció conseguir otro espacio en cualquier otra escuela "indeterminada" de la capital, pero esta no era una solución aceptable, siendo la Universidad Popular un fruto del barrio. Entonces, la gente de Boedo, con ayuda de la prensa especializada, pidió a las autoridades que les dieran otro establecimiento dentro del mismo barrio, ya que una institución tan importante no debía desaparecer. Uno de los periodistas de un diario local comentaba:

"Quien exige en tales términos la mudanza, es nada menos que el Consejo Nacional de Educación. Dicho de otro modo, resulta que el Estado, a quien ayuda y suple la UPdB, tomando para sí funciones de cultura pública que el gobierno es incapaz de realizar, se comporta en este caso como un vulgar casero sórdido ante un inquilino insolvente: lo arroja de su casa por la fuerza [...]. Si en este país los ricos tuvieran el sentido humanitario que ennoblece el caudal de los ricos de otros países la UPdB tendría a estas horas un edificio propio y magnífico. Exigimos que siga teniendo, por lo menos el desganado préstamo de un rincón de escuela fiscal" ${ }^{\prime 2}$.

Lo extraño e inexplicable fue que las autoridades del Consejo Escolar VI dispusieran la clausura de las clases de la UPdB, afectando de esta manera el normal desarrollo de los 1400 alumnos que concurrían diariamente a dicho establecimiento.

\section{La Sociedad Luz: Universidad Popular del Partido Socialista Argentino}

La Sociedad Luz fue una experiencia de Universidad Popular impulsada por el Partido Socialista Argentino, que comenzó sus actividades en la ciudad de Buenos Aires en el año 1899 y que tenía por objeto "la instrucción del pueblo”. La iniciativa partió de Mauricio Kliman, un estudiante de Ingeniería quien, a principios de 1899, comenzó a

62 Archivo de la Junta de Altos Estudios Históricos de Boedo, citado en Mónica Villa, José González Castillo. Militante de lo popular, 157. 
diagramar una entidad cultural destinada a la enseñanza con proyecciones luminosas, que en ese entonces hacían furor en Europa. Este entusiasmo por la difusión cultural y científica fue compartido por Juan B. Justo, fundador del Partido Socialista, y Ángel Mariano Giménez, médico higienista, quienes facilitaron el histórico local del Partido Socialista de la calle México para la concreción de la iniciativa de Kliman. Las primeras actividades consistieron en las conferencias y proyecciones de divulgación sobre diferentes temas, como "El sistema planetario y la tierra" $"$.

\section{Imagen No. 3}

Memoria del Ejercicio 1940 de la Universidad Popular de Boedo. La «Post Escuela»

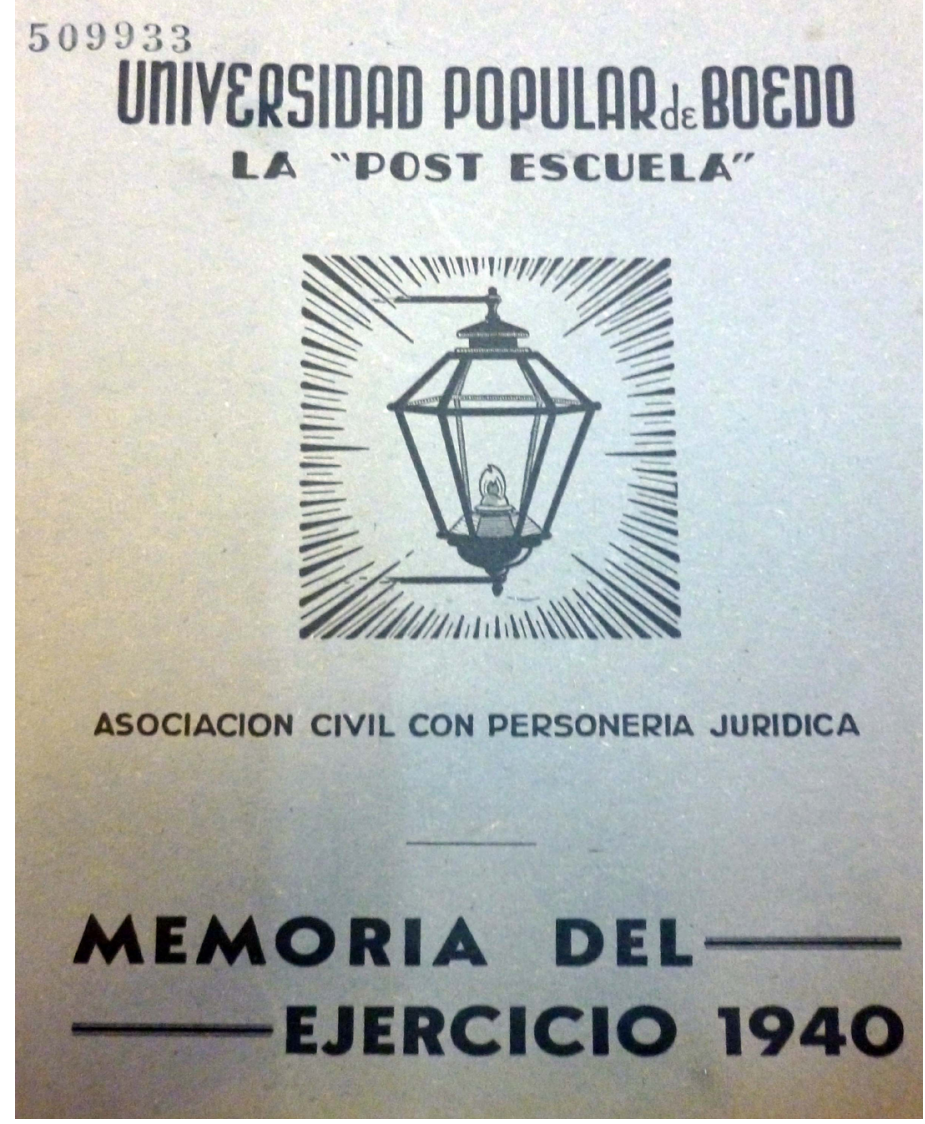

Fuente: Biblioteca Nacional Mariano Moreno, Buenos Aires.

63 Dora Barrancos, La escena iluminada. Ciencias para trabajadores, 1890-1930 (Buenos Aires: Editorial Plus Ultra, 1996). 
En la autobiografía política del militante socialista Nicolás Repetto ${ }^{64}$ se describe la fundación de esta institución y algunas de sus actividades. Repetto cuenta que a Juan B. Justo ${ }^{65}$, quien conocía la deficiente instrucción de los afiliados en general por aquella época, le preocupaba el problema cultural dentro de las filas del Partido, y se proponía suplir esa deficiencia creando una Universidad Popular encargada de divulgar en la masa del pueblo nociones generales de ciencia y problemas de actualidad, moviéndole al mismo tiempo a participar en la lucha por la solución de estos problemas. Justo tenía listo el programa de materias, el plan de organización de la enseñanza y hasta el nombre de la institución, que se llamaría Sociedad Luz. Kliman enseñó astronomía varios años con mucho éxito a los numerosos obreros que concurrían a la Casa Obrera de la calle México 2070, en el barrio porteño de Monserrat ${ }^{66}$.

Dicha sede de la calle México era también, como dijimos, la sede del Partido Socialista, una casa de amplias dimensiones y construida de acuerdo a sus fines y necesidades peculiares. Era de propiedad del compañero Haupt, un antiguo obrero alemán a quien se le había expulsado de su país en virtud de la ley bismarckiana contra los socialistas, pero que en Argentina se había enriquecido explotando un taller metalúrgico, cuyas utilidades invertía en la construcción de locales para el Partido, las sociedades gremiales y las cooperativas. La sede resultó ser una especie de escuela en la que todos se sentían estimulados a la

64 Nicolás Repetto (Buenos Aires, 21/10/1871 - Vicente López, Provincia de Buenos Aires, 29/11/1965). Médico cirujano, escritor, parlamentario y dirigente socialista, fue líder del ala moderada del socialismo argentino. Consultado en Horacio Tarcus (dir.), Diccionario biográfico de la izquierda argentina. De los anarquistas a la «nueva izquierda», 1870-1976 (Buenos Aires: Emecé, 2007), 326.

65 Juan Bautista Justo (Buenos Aires, 28/6/1865 - Los Cardales, Provincia de Buenos Aires, 8/1/1928). Médico, docente, ensayista político, legislador, periodista, traductor, conferencista, figura fundacional y máximo dirigente del socialismo argentino de proyección internacional. Para más datos biográficos, ver Horacio Tarcus (dir.), Diccionario biográfico de la izquierda argentina, 565.

66 Nicolás Repetto, Mi paso por la política: de Roca a Yrigoyen (Buenos Aires: Santiago Rueda, 1956), 27. No hemos encontrado en los documentos una mención a la "República de Monserrat", pero sí hallamos mención a la "República de Barracas", barrio al que se trasladaría posteriormente la Sociedad Luz. Dicha "república" fue de creación más tardía, en el año 1960. Véase Pablo Carlos de Rosa Barlaro, La República de Barracas (Buenos Aires: Blogs lanacion.com, 8 de junio de 2012), http:// blogs.lanacion.com.ar/archivoscopio/archivoscopio/la-republica-de-barracas/ [fecha de consulta: 10 de marzo de 2019]. 
acción. La labor cultural tenía por instrumentos principales la biblioteca, las conferencias, los cursos breves dictados por la Sociedad Luz y el instructivo material de lectura que ofrecía el periódico La Vanguardia. La Sociedad Luz despertó mucho interés y contribuyó poderosamente a la difusión de los conocimientos científicos más diversos: Kliman explicaba con muchas proyecciones y muy pocas palabras los aspectos más interesantes de la astronomía; el doctor Augusto Bunge se especializó en los problemas vinculados a la salud humana, a la higiene general y a la vivienda obrera; el entonces estudiante de medicina Enrique Dickmann ${ }^{67}$ dictaba cursos elementales de anatomía y fisiología humana; el también estudiante de medicina Ángel M. Giménez dictaba cursos sobre salud sexual y la defensa contra las afecciones venéreas. Otros cursos que se dictaron fueron de historia universal, elementos de literatura, gramática castellana, química experimental y evolución orgánica, por los profesores Enrique del Valle Iberlucea, Alberto Gerchunoff, Fenia Cheertcoff de Repetto, Carlos Roqué ${ }^{68}$ y Nicolás Repetto, respectivamente ${ }^{69}$.

El salón de la calle México resultó pequeño para contener al gran número de obreros que concurrían. El doctor Ángel M. Giménez creó nuevos cursos, instaló una biblioteca, organizó visitas colectivas dominicales a museos, monumentos históricos, edificios públicos, alrededores pintorescos, etcétera, y editó decenas de miles de folletos sobre los temas más diversos, con predominio de los problemas escolares, de la educación laica y del estudio de la evolución en todos sus aspectos. Giménez le otorgó a la Sociedad, casi exclusivamente de su peculio, el hermoso edificio de la calle Suárez al 1301, levantado expresamente en un barrio obrero como el de Barracas, "para contribuir a la elevación cultural de la gran masa de trabajadores que lo habitan"70.

67 Para una aproximación a la trayectoria estudiantil de Enrique Dickmann puede consultarse: Pablo Buchbinder, ¿Revolución en los claustros? La Reforma Universitaria de 1918 (Buenos Aires: Sudamericana, 2008), 24-25.

68 A Carlos Roqué lo remplazaría el profesor doctor Horacio Daminovich como encargado para dar el curso de química experimental.

69 Repetto, Mi paso por la política, 31-64

70 Repetto, Mi paso por la política, 68. 
Imagen No. 4

Antología Antialcohólica de Ángel Giménez, editada por la Sociedad Luz en 1933

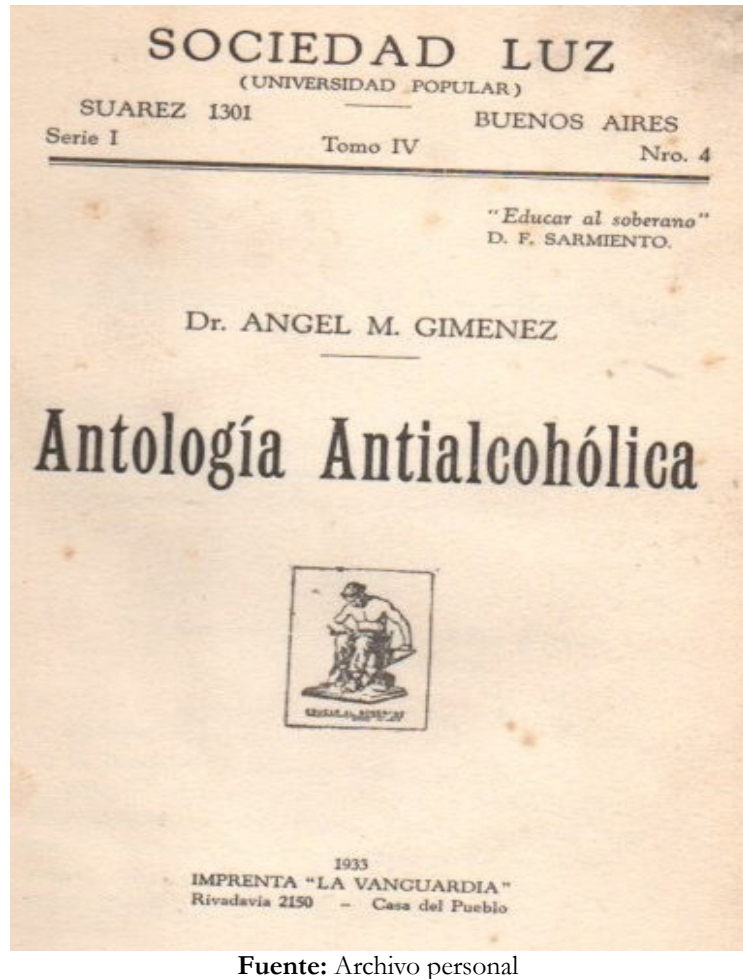

Persiguiendo nuestro objetivo de tener un conocimiento más acabado del nexo entre las identidades barriales y las Universidades Populares (interrogante que no se clausura en este trabajo), hemos encontrado en algunos autores una confusión entre la Sociedad Luz y la Universidad Popular de La Boca. Un ejemplo lo tenemos en la obra La visión de una Universidad Popular, del científico chileno Carlos Oliver Schneider ${ }^{71}$ :

71 Carlos Oliver Schneider (Canelones, Uruguay, 15 de septiembre de 1899 - Concepción, Chile, 12 de junio de 1949). Científico uruguayo-chileno, que fue profesor de la Universidad Popular de Concepción (Chile). Para mayor información sobre Oliver Schneider se puede consultar Boris Márquez Ochoa, Carlos Oliver Schneider. Naturalista e historiador de Concepción (Concepción: Ediciones del Archivo Histórico de Concepción, 2015), así como Parmenio Yánez A., "El profesor Carlos Oliver Schneider, un precursor de la biología marina en Chile", Revista de Biología Marina (Valparaíso) (enero de 1950), https://revbiolmar.uv.cl/escaneados/2-97.pdf [fecha de consulta: 8 de marzo 2019]. 
"En Argentina, en Buenos Aires, funciona desde hace años, la Universidad Popular de La Boca, que hasta cierto punto tiene una tendencia socialista (sic) y que he tenido el gusto de visitar detenidamente. Ahí se ha dictado un curso sobre Astronomía por el profesor Camilo Mayer, que tuvo tal rotunda resonancia que un "ricacho", como lo llaman allá, don Rómulo Chopitea, se entusiasmó hasta costear la publicación ilustrada del curso de Mayer"'72.

No hemos encontrado evidencia que nos permita sostener que la experiencia de la UPdLB estuviera orientada por una "tendencia socialista", como afirma Oliver Schneider, y ni siquiera encontramos en los registros que guarda su archivo histórico documentos que mencionen cursos de astronomía o al profesor Mayer. Esta confusión se debió posiblemente a que los barrios de la ciudad de Buenos Aires no suelen tener fronteras geográficas claras, y sus límites son muy opacos, como sucede en el caso de los barrios de La Boca y Barracas. Suele ser más fácil definir a un barrio por su centro -donde se condensa la identidad del barrio- que por su periferia - donde la identidad se diluye-. Oliver Schneider comete un error, que al día de hoy resulta común, al confundir ambas instituciones:

"Recuerdo que en ocasión de mi visita, uno de los dirigentes de la Sociedad Lux (sic), que es la sostenedora de esa Universidad Popular, mi distinguido amigo el doctor Ángel Jiménez, me recalcaba el hecho de que había muchas formas de analfabetismo de orden superior, que consiste, no sé si me lo explicaba así por saberme naturalista, que consistía, digo, en no saber deletrear en el hermoso libro de la Naturaleza" ${ }^{73}$.

En otra de sus obras, Hacia la Cultura Colectiva, Oliver Schneider confunde nuevamente las instituciones de la Universidad Popular de La Boca y la Sociedad Luz:

"En nuestro continente voy a mencionar la Universidad Popular de La Boca, en Buenos Aires, sostenida por la Sociedad Lux (sic), y que es una

72 Carlos Oliver Schneider, La visión de una Universidad Popular. Conferencia dictada en el acto inaugural de la Universidad Popular de Temuco (Concepción: Talleres Gráficos J. A. Arteaga, 1932), 27.

73 Carlos Oliver Schneider, La visión de una Universidad Popular, 27. 
institución vigorosa, que presta positivos servicios a la población de un extenso barrio de esa capital.

La obra de esta Universidad es tan extensa e intensa, que un día sus organizadores se empeñaron en mejorar el bienestar de la población y tras de una razonada propaganda consiguieron hacer bajar el precio del pan (sic). Otra vez iniciaron una formidable propaganda de la avicultura casera, no de la avicultura en grande escala, sino de la pequeña avicultura, obtuvieron que mucha gente de escasos recursos no solo tuviera sus gallinas, sino que las criaran bien, productivamente. Otra campaña, dedicada a los chacareros, los convenció de la necesidad de plantar un tipo de maíz que se cosechara cuarenta días después de sembrado, y hasta los niños de los pequeños agricultores llegó la obra de Universidad Popular, enseñándoles a criar cada uno un chancho por su cuenta y riesgo, para obtener con su venta el dinero necesario que costeara sus estudios elementales. Eso es lo que se llama hacer obra" ${ }^{\prime 7}$.

A diferencia de lo que relata en La visión de una Universidad Popular, en Hacia la Cultura Colectiva Oliver Schneider relata los cursos, propaganda y campañas que fueron llevadas a cabo por la UPdLB y que sí se pudieron verificar en el archivo histórico de esta institución, pero continúa sin diferenciar ambas instituciones.

\section{CONCLUSIÓN: LA INTERRELACIÓN ENTRE LAS IDENTIDADES}

BARRIALES Y LAS PERTENENCIAS INSTITUCIONALES EN EL CASO DE LAS Universidades Populares

Al promediar la década de 1930 podemos identificar un considerable aumento en la cantidad de Universidades Populares a lo largo y ancho de la Argentina. Muchas de ellas se congregaron para conformar una especie de federación denominada Universidades Populares Argentinas (UPA); otras se mantuvieron autónomas, y sospechamos que algunas, con una orientación más izquierdista, conformaron su propio agrupamiento. Las UPA realizaron innumerables eventos y produjeron diferentes materiales de divulgación, entre ellos la Revista de las Universidades Populares Argentinas, que editaron para informar sobre su desarrollo.

74 Carlos Oliver Schneider, Hacia la Cultura Colectiva (Concepción: Ediciones de la Universidad Popular de Concepción, Talleres Gráficos J.A. Arteaga, 1932), 23. 
En el folletín Cuatro Palabras sobre las UPA (Universidades Populares Argentinas), de 1939, se contabilizan las siguientes Universidades Populares nucleadas en esta organización ${ }^{75}$ :

Universidades Populares que funcionan en la capital y pueblos suburbanos:

\begin{tabular}{|l|l|}
\hline Universidad Popular & Local \\
\hline Bartolomé Mitre & Varela 358 \\
T. Achával Rodríguez & Carabobo 253 \\
Guillermo Rawson & R.L. Falcón 6702 \\
José M. Estrada & Charcas 3577 \\
José C. Paz & Bolívar 1235 \\
Nicolás Avellaneda & Besares 2900 \\
Victorino Ortega & Hortiguera 742 \\
José Cortejarena & V. Martínez 1780 \\
Miguel Navarro Viola & Sadi Carnot 234 \\
Roque Sáenz Peña & Warner 1816 \\
Eleodoro Lobos & Gorriti 5470 \\
Francisco Pico & Quesada 2343 \\
Victorino de la Plaza & Tellier 1171 \\
José de San Martín & Homero 1157 \\
Pedro Goyena & Almafuerte 630 \\
Marco M. Avellaneda & Larrea 854 \\
D.F. Sarmiento & San Fernando \\
I Figueroa Alcorta & Adrogué \\
\hline
\end{tabular}

Universidades Populares que funcionan en el interior:

\begin{tabular}{|l|l|}
\hline Universidad Popular & Local \\
\hline Campana & Campana \\
Baradero & Baradero \\
Sarmiento & La Plata \\
Mariano Moreno & Necochea \\
José Hernández & Azul \\
Luis Caronti & Bahía Blanca \\
Manuel Belgrano & Tandil \\
Zarate & Zarate \\
Escobar & Escobar \\
Concordia & Entre Ríos \\
Concepción del Uruguay & Entre Ríos \\
Colón & Entre Ríos \\
Dolores & Dolores \\
\hline
\end{tabular}

75 Fernando de Prat Gay y Juan José Soiza Reilly, Cuatro Palabras sobre las UPA (Universidades Populares Argentinas) (Buenos Aires: Talleres Gráficos Denuble, 1939), 23. 


\begin{tabular}{|l|l|}
\hline Universidad Popular & Local \\
\hline San Rafael & Mendoza \\
Mendoza & Mendoza \\
Córdoba & Córdoba \\
Santiago del Estero & S. del Estero \\
La Banda & S. del Estero \\
San Juan & San Juan \\
Santa Rosa & La Pampa \\
Resistencia & Chaco \\
Mar del Plata & Mar del Plata \\
\hline
\end{tabular}

En esta relación podemos contar 18 Universidades Populares que funcionaron en la ciudad de Buenos Aires y pueblos suburbanos, de las cuales ninguna tiene el nombre del barrio en el cual se emplazaron. De las 22 Universidades Populares que funcionaron en el interior del país el panorama es un poco más diverso. 17 hacen referencia al sitio donde están radicadas, pero esta consideración nos puede llevar a un error ya que pudimos saber, por ejemplo, que la Universidad Popular de Baradero se llamaba Mariano Moreno ${ }^{76}$.

Podemos suponer que la adopción del nombre vinculado con algún prócer de la historia argentina por parte de las Universidades Populares de la capital y los pueblos suburbanos, que pretendían realizar una "educación nacional" con el fin de preparar a sus estudiantes "para la lucha por la vida", al optar por abandonar la identificación barrial, utilizaban su nombre como un dispositivo pedagógico más para la nacionalización de las masas ${ }^{77}$.

Por el contrario, en el caso de la Universidad Popular de Boedo debemos tener en cuenta que el barrio de Boedo, si bien alude al nombre de

76 J. Alejandro Barbich, Historia de Santiago del Baradero (Buenos Aires: Editorial Amerindia, 1980), 62-63.

77 Con respecto a los nombres de las Universidades Populares creemos que sucede algo muy similar a lo descrito por Camarero para el caso de las bibliotecas y centros de cultura comunistas. Los nombres de las Universidades Populares, al igual que dichos centros, remiten a un conjunto heterogéneo de próceres provenientes de la tradición liberal nacionalista, así como a algunos personajes del "progresismo" argentino, y no a valores y símbolos (aunque estos pueden aparecer en escudos o en subtítulos de las Universidades). Para el caso de las bibliotecas comunistas consúltese la obra de Camarero, A la conquista de la clase obrera: los comunistas y el mundo del trabajo en la Argentina, 1920-1935, 223. 
Mariano Boedo ${ }^{78}$, se constituyó desde una arteria principal que para los vecinos y todos los porteños fue conocida como Boedo a secas, perdiéndose la referencia al prócer, y que el nombre de la Universidad Popular se debía más a la arteria comercial principal del barrio que al prócer. Del mismo modo podemos suponer que aquellas Universidades Populares que decidieron mantener una sólida identificación barrial/ territorial seguramente pudieron apelar a un chovinismo localista para fomentar la solidaridad con eventos diversos que realizaban para financiar sus actividades.

Siguiendo a Hoggart ${ }^{79}$, quien sugirió que las variaciones estructurales, geográficas, ambientales o étnicas complejizaban y heterogeneizaban las experiencias de una cultura obrera, que nace siempre en ambientes específicos (barrio, fábrica o comunidad local) y que, por tanto, se trata de una cultura de comunidad de núcleos sociales restringidos, sostenemos que un aporte para el conocimiento de la cultura obrera se puede realizar desde sus barrios y las instituciones de estos. El barrio fue también un enclave importante para la primera Universidad Popular que inauguró en 1899 Georges Deherme en Francia, ya que la asentó en la calle Faubourg ${ }^{80}$ Saint-Antoine en París, un barrio popular del $11^{\circ}$ distrito $^{81}$.

En tal sentido consideramos que las crónicas de Soiza Reilly, publicadas en Caras y Caretas, prensa de masiva difusión, y posiblemente replicadas en emisiones radiales, son útiles para ver de qué forma las Universidades Populares aportaban una cuota de prestigio en la constitución de las identidades barriales y cómo las Universidades Populares

78 Mariano Joaquín Boedo (Salta, 25 de julio de 1782 - Buenos Aires, 9 de abril de 1819), fue un abogado y político argentino, diputado por Salta en el Congreso de Tucumán de 1816. Véase Vicente Cutolo, Nuevo Diccionario Biográfico Argentino (1750-1930), Vol. I (Buenos Aires: Elche, 1968).

79 Hoggart, La cultura obrera en la sociedad de masas.

80 Faubourg es un antiguo término francés de significado similar a "suburbio" (actualmente denominado banlieue en francés). Su primera forma es forsbourg, derivado del latín foris, "fuera de", y del latín vulgar burgum (de origen germánico), "ciudad" o "fortaleza". En Alain Rey, Dictionnaire historique de la langue française (Paris: Le Robert, 2006). En este sentido, el suburbio/arrabal y la experiencia de las Universidades Populares, tanto francesas como argentinas, comparten un lazo similar.

81 Lucien Mercier, "La educación popular a través de la Universidad Popular en la Francia del primer siglo XX", Historia de la Educación (Salamanca) No. 20 (2001): 118. 
se retroalimentaban del prestigio que otorgaba ser "la" Universidad Popular del barrio. Esa interrelación configuraba el despliegue de una red de vínculos barriales sumamente importante en la conformación de las circunscripciones electorales, posiblemente diluyendo identidades clasistas más autónomas. Muchas veces el primer contacto para comenzar a tejer y a expandir dicha red no se constituía solo con la estatalidad, sino desde el faro cultural que significaba la radicación por la presencia de una escuela pública en el barrio. El entramado de esta red de vínculos tiene sus nodos tanto intra muros como extra muros de los barrios $^{82}$.

En su alegato que autodenominó "Memorias de una época materialista”, de más de seiscientas páginas, escrito tras ser expulsado del Honorable Concejo Deliberante de la Capital Federal en el año 1941, el doctor Luis L. Boffi incluyó en su capítulo tercero, que llamó "Mi foja de servicios", su desempeño como Vicepresidente de la Universidad Popular Bernardino Rivadavia, Presidente Honorario de la Universidad Popular La Argentina y Consejero de la Universidad Popular Mariano Moreno $^{83}$. Ello nos permite inferir que no solo los barrios gozaban del prestigio de tener una Universidad Popular, sino que también estas nutrían de prestigio personal y político a sus integrantes.

Así es como las Universidades Populares con sede en la ciudad de Buenos Aires funcionaron generalmente en edificios escolares y tuvieron las características de las academias dedicadas a la enseñanza de múltiples disciplinas, como contabilidad, dibujo, pintura, artes decorativas, costura, cocina, motores, radiotelefonía, electricidad, relojería y tipografía, entre otras. Por ejemplo, la Universidad Popular Bartolomé Mitre inició sus actividades el 16 de junio de 1936 en un local propio

82 Se entiende como red social un complejo sistema relacional que permite la circulación de bienes y servicios materiales e inmateriales, dentro de un conjunto de relaciones establecidas entre sus miembros, afectándolos de forma desigual, directa o indirectamente. Sobre el análisis de las redes sociales y vinculares remitimos a Michel Bertrand, "Del actor a la red: análisis de redes e interdisciplinaridad", Nuevo Mundo Mundos Nuevos (Noviembre de 2009), https://doi.org/10.4000/nuevomundo.57505 [fecha de consulta: 30 de marzo 2019].

83 Luis L. Boffi, 1259 días concejal de la Ciudad de Buenos Aires. Memorias de una época materialista (Buenos Aires: Lotito Hermanos y Compañia Impresores, 1943), 29. 
construido en Varela 358. El edificio luego fue vendido al Consejo Nacional de Educación, que ocupó las instalaciones con la Escuela No. 8 del Distrito Escolar XI. Otras instituciones similares que funcionaron fueron la Universidad Popular Intendente Torcuato de Alvear (su primer presidente fue el Dr. Ernesto León Odena), que en octubre de 1938 inauguró su sede en Directorio 3043; la Universidad Popular de Flores Sud, que funcionó entre 1932 y 1948 en la Escuela No. 6 del Distrito Escolar XI (Varela 1040); la Universidad Popular Victorino Ortega, que tenía por sede la Escuela No. 9 del Distrito Escolar XI (Cnel. Ramón L. Falcón 2934); la Universidad Popular Tristán Achával Rodríguez en la Escuela No. 15 del Distrito Escolar XI (Carabobo 253), y la Universidad Popular José de San Martín en el local de la desaparecida Escuela No. 8 del Distrito Escolar XIX (Pergamino 1528), todas estas en el barrio de Flores ${ }^{84}$.

En sintonía con lo que Sandra Carli describe para la mediación de las asociaciones, centros y sociedades de la educación popular ${ }^{85}$, en las Universidades Populares encontramos también cómo estas propuestas pueden ser pensadas como intersticios a través de los cuales sectores de la sociedad civil intentaron flexibilizar, democratizar, resignificar, alterar en suma en diferente medida, la estructura y funcionamiento del sistema educativo estatal.

Estas experiencias resultaron posibles gracias a la participación de docentes y a establecimientos de educación estatal que en muchas oportunidades eran compartidos con las Universidades Populares, en lo que hoy podemos identificar como el circuito de "educación oficial". El barrio resultó ser territorio particularmente fértil para que anclaran las Universidades Populares. Las identidades del barrio y de la Universidad Popular se retroalimentaron cuando tomaron los nombres del territorio que habitaban, desechando el nombre de próceres de la historia argentina o el de celebridades barriales, sin despojarse del objetivo de

84 Ángel Prignano, Historia abreviada del barrio de Flores (Buenos Aires: Ediciones BP, 2014).

85 Sandra Carli, "Infancia y sociedad: la mediación de las asociaciones, centros y sociedades populares", en Historia de la Educación Argentina II. Sociedad civil y Estado en los orígenes del sistema educativo argentino, ed. Adriana Puiggrós (Buenos Aires: Galerna, 1991), 26. 
impartir una "educación nacional". Al mismo tiempo, estos barrios aumentaron su prestigio al contar con dichas Universidades, que retratadas en diferentes crónicas de época incluso dejaron de ser reconocidas como Universidades Populares y pasaron a ser referidas como Universidades - a secas- del barrio donde se radicaban. Por ejemplo, la Universidad Popular de La Boca deviene en la Universidad de La Boca. De esta manera se produjo una interesante interacción en la apelación discursiva para la construcción de dos identidades -la nacional y la local- que durante el siglo XX pierden antagonismo. En el caso de la Universidad Popular Sociedad Luz, donde el carácter de universitario se convirtió en un mero epígrafe del de Sociedad Luz, evidenciamos cómo el vínculo partidario obstruyó esta relación con lo barrial e impidió toda retroalimentación, incluso tras su mudanza del barrio de Monserrat al proletario barrio de Barracas, asemejándola a una escuela de cuadros.

\section{Bibliografía}

\section{Fuentes Primarias}

\section{Publicaciones periódicas}

Atlántida (revista quincenal).

Caras y Caretas (semanario).

Crítica (diario).

Revista de las Universidades Populares Argentinas (publicación mensual).

\section{Memorias}

Canop, Santiago. Obra y acción de las Universidades Populares Argentinas. Buenos Aires: Talleres Gráficos Macagno Hnos. \& Landa, 1941.

De Prat Gay, Fernando y Juan José Soiza Reilly. Cuatro Palabras sobre las UPA (Universidades Populares Argentinas). Buenos Aires: Talleres Gráficos Denuble, 1939.

Universidad Popular de Boedo. La «Post Escuela». Memoria del Ejercicio 1937. Buenos Aires: UPDB, 1937.

Universidad Popular de Boedo. La «Post Escuela». Memoria del Ejercicio 1940. Buenos Aires: UPDB, 1941. 
Universidad Popular de La Boca. 50 Aniversario. Universidad Popular de La Boca, 1917 - 2 de Junio - 1967. Medio siglo dedicado a la educación del Pueblo. Buenos Aires: Talleres Gráficos el Triángulo, 1968.

\section{Otras fuentes primarias}

Oficina Cartográfica Bemporat y A. Bemporat (comp.). Plano centenario de la Capital Federal: plano de conjunto del catastro de la Capital, 1816-1916. Buenos Aires: Oficina Cartográfica Bemporat, 1916.

Oliver Schneider, Carlos. Hacia la Cultura Colectiva. Concepción: Ediciones de la Universidad Popular de Concepción, Talleres Gráficos J.A. Arteaga, 1932.

Oliver Schneider, Carlos. La visión de una Universidad Popular. Conferencia dictada en el acto inaugural de la Universidad Popular de Temuco. Concepción: Talleres Gráficos J.A. Arteaga, 1932

Rahola, Federico. Sangre Nueva. Impresiones de un viaje á la América del Sud. Barcelona: Tipografía "La Académica", 1905.

Soiza Reilly, Juan José. "Viaje a través de los barrios porteños. La República de Boedo". Caras y Caretas, Buenos Aires, 11 de octubre de 1930.

Soiza Reilly, Juan José. "Viaje a través de los barrios de Buenos Aires. La República Genovesa de La Boca". Caras y Caretas, Buenos Aires, 18 de octubre de 1930.

Vidal, Blas. "La República de la Boca. Los Carbonarios - La Vendetta La Maffia - La Mano Negra". Caras y Caretas, Buenos Aires, 4 de septiembre de 1904.

\section{Fuentes secundarias}

Arlt, Roberto. Aguafuertes porteñas. Buenos Aires: Losada, 1973. Barbich, J. Alejandro. Historia de Santiago del Baradero. Buenos Aires: Editorial Amerindia, 1980.

Barrancos, Dora. La escena iluminada. Ciencias para trabajadores, 18901930. Buenos Aires: Editorial Plus Ultra, 1996.

Barriera, Darío G. Abrir puertas a la tierra. Microanálisis de la construcción de un espacio político. Santa Fe, 1573-1640. Santa Fe: Museo Histórico Provincial Brigadier Estanislao López, 2013. 
Bertrand, Michel. "Del actor a la red: análisis de redes e interdisciplinaridad”. Nuevo Mundo Mundos Nuevos (Noviembre de 2009). https://doi.org/10.4000/nuevomundo.57505.

Boffi, Luis L. 1259 días concejal de la Ciudad de Buenos Aires (Memorias de una época materialista). Buenos Aires: Lotito Hermanos y Compañia Impresores, 1943.

Buchbinder, Pablo. ¿Revolución en los claustros? La Reforma Universitaria de 1918. Buenos Aires: Sudamericana, 2008.

Bucich, Antonio J. Ubicación boquense del Dr. Tomás A. Le Bretón. Cuadernos de la Boca del Riachuelo, 25. Buenos Aires: Escuela de Artes Gráficas, 1967.

Camarero, Hernán. A la conquista de la clase obrera: los comunistas y el mundo del trabajo en la Argentina, 1920-1935. Buenos Aires: Siglo XXI, 2007.

Carli, Sandra. "Infancia y sociedad: la mediación de las asociaciones, centros y sociedades populares". En Historia de la Educación Argentina II. Sociedad civil y Estado en los orígenes del sistema educativo argentino, editado por Adriana Puiggrós. Buenos Aires: Galerna, 1991, 13-46.

Castorina, José Antonio (coord.). Construcción conceptual y representaciones sociales. El conocimiento de la sociedad. Buenos Aires: Miño y Dávila, 2005.

"Cuando la República de La Boca se independizó”. Diario Popular, Buenos Aires, 9 de febrero de 2017. https://www.diariopopular. com.ar/barracas-la-boca/cuando-la-republica-la-boca-se-independizo-n300656

Cutolo, Vicente. Historia de los barrios de Buenos Aires. Buenos Aires: Elche, 1998.

Cutolo, Vicente. Nuevo Diccionario Biográfico Argentino (1750-1930), Vol. I. Buenos Aires: Elche, 1968.

De Privitellio, Luciano. Vecinos y ciudadanos. Política y sociedad en la Buenos Aires de entreguerras. Buenos Aires: Siglo Veintiuno, 2003.

De Rosa Barlaro, Pablo Carlos. La República de Barracas. Buenos Aires: Blogs lanacion.com, 8 de junio de 2012. http://blogs.lanacion. com.ar/archivoscopio/archivoscopio/la-republica-de-barracas/.

Del Castillo, Dr. Benjamín E. "La obra cultural de las U.P.A.”. Revista de las Universidades Populares Argentinas (febrero de 1940). 
Del Pino, Diego. "José González Castillo y el mundo literario de Boedo". Todo es Historia No. 311 (junio de 1993).

Di Meglio, Gabriel. ¡Viva el bajo pueblo! La plebe urbana de Buenos Aires y la política entre la Revolución de Mayo y el rosismo. Buenos Aires: Prometeo, 2007.

Ferrari, Marcela. Los políticos en la República Radical. Prácticas políticas y construcción de poder. Buenos Aires: Siglo XXI, 2008.

Gastellu, Sofía. "La Justicia de Paz en la ciudad de Buenos Aires. La dimensión territorial de una justicia de proximidad (1821-1854)". En Justicias situadas. Entre el Virreinato Rioplatense y la República Argentina (1776-1864), editado por Darío G. Barriera. La Plata: FaHCE-Universidad Nacional de La Plata, 2017.

Giunta, Roberto. "Revolución industrial y barrio". En Buenos Aires. El libro del Barrio. Teorías y Definiciones, editado por Liliana Barela y Mario Sabugo. Buenos Aires: Instituto Histórico de la Ciudad de Buenos Aires, 2004, 107-122.

González Leandri, Ricardo. "La nueva identidad de los sectores populares". En Crisis económica, avance del Estado e incertidumbre política (1930-1943), editado por Alejandro Cataruzza, Vol. VII, Nueva Historia Argentina. Barcelona: Sudamericana, 2011.

Gorelik, Adrián. La grilla y el parque. Espacio público y cultura urbana en Buenos Aires, 1887-1936. Buenos Aires: Universidad de Quilmes, 1998.

Gorelik, Adrián, y Graciela Silvestri. "Imágenes al sur. Sobre algunas hipótesis de James Scobie para el desarrollo de Buenos Aires". Anales del Instituto de Arte Americano e Investigaciones Estéticas «Mario J. Buschiazzo». FADU-UBA, No. 27-28 (1991).

Granara Insúa, Rubén. La República de La Boca. Buenos Aires: Ed. La Boca del Riachuelo, 1986.

Hoggart, Richard. La cultura obrera en la sociedad de masas. Buenos Aires: Siglo XXI, 2013.

Horowitz, Joel. El radicalismo y el movimiento popular (1916-1930). Buenos Aires: Edhasa, 2015.

Korn, Francis. Los huéspedes del 20. Buenos Aires: Sudamericana, 1974.

Kusch, Rodolfo. Obras completas. Tomo I. Buenos Aires: Fundación Ross, 2007. 
"La Comuna Libre de Montmartre". http://www.montmartre-guide. com/es/historias_montmartre/la-comuna-libre-de-montmartre/.

La Rocca, Malena. "Las prácticas de la cultura y educación popular: la lucha por la ocupación de espacios sociales". En Trabajadores y Educación en Argentina. De las estrategias sindicales a la acción de los movimientos sociales, compilado por Roberto Elisalde, Marina Ampudia, Juan Pablo Nardulli y Joaquín Calvagno. Buenos Aires: Ed. Buenos Libros, 2011, 183-200.

Llanes, Ricardo M. El barrio de Almagro. Buenos Aires: Municipalidad de la Ciudad de Buenos Aires, 1968 (Cuadernos de Buenos Aires, Vol. XXVI).

Lomba, Aníbal. Boedo. Un barrio con historias. Buenos Aires: Ministerio de Cultura. Gobierno de la Ciudad de Buenos Aires, Comisión para la Preservación del Patrimonio Histórico Cultural de la Ciudad de Buenos Aires, 2006.

Lopa, Ricardo. Cátulo Castillo. Un porteño de Boedo. Buenos Aires: Agebe, 2011.

Lopa, Ricardo. Sur. Barrio de tango, amor y revolución. Buenos Aires: Agebe, 2014.

Márquez Ochoa, Boris. Carlos Oliver Schneider. Naturalista e historiador de Concepción. Concepción: Ediciones del Archivo Histórico de Concepción, 2015.

Mercier, Lucien. "La educación popular a través de la Universidad Popular en la Francia del primer siglo XX”. Historia de la Educación (Salamanca) No. 20 (2001): 117-135.

Paredes, Daniel, Dora Bordegaray, Lida González y Marcela Vilela (comps.). Buenos Aires, voces al sur. Construcción de identidades barriales. Buenos Aires: Instituto Histórico de la Ciudad de Buenos Aires, 2006.

Persello, Ana Virginia. El partido radical. Gobierno y oposición, 19161943. Buenos Aires: Siglo XXI, 2004.

Prignano, Ángel. Historia abreviada del barrio de Flores. Buenos Aires: Ediciones BP, 2014.

Puiggrós, Adriana (comp.). Historia de la Educación en la Argentina. Vol. II: La educación argentina desde la Reforma Saavedra Lamas

hasta el fin de la década infame. Buenos Aires: Galerna, 2000.

Repetto, Nicolás. Mi paso por la política: de Roca a Yrigoyen. Buenos Aires: Santiago Rueda, 1956. 
Rey, Alain. Dictionnaire historique de la langue française. Paris: Le Robert, 2006.

Rock, David. El Radicalismo Argentino. 1890-1930. Buenos Aires: Amorrortu, 2010.

Romero, Luis Alberto y Leandro H. Gutiérrez. Sectores populares, cultura y política. Buenos Aires en la entreguerra. Buenos Aires: Sudamericana, 1995.

Sarlo, Beatriz. La máquina cultural. Maestras, traductores y vanguardistas. Buenos Aires: Siglo XXI, 2017.

Scobie, James. Buenos Aires. Del centro a los barrios, 1870-1910. Buenos Aires: Solar, 1977.

"Seis Poetas del Tango. Cátulo Castillo". La Maga, edición especial de colección, No. 16 (diciembre de 1995).

Silvestri, Graciela. El color del río. Historia cultural del paisaje del Riachuelo. Bernal: Universidad Nacional de Quilmes-Prometeo, 2012. Spinetto, Horacio. Pizzerías de valor patrimonial de Buenos Aires. Buenos Aires: Dirección General de Patrimonio e Instituto Histórico, 2008.

Tarcus, Horacio (dir.). Diccionario biográfico de la izquierda argentina. De los anarquistas a la «nueva izquierda», 1870-1976. Buenos Aires: Emecé, 2007.

Troilo, Aníbal (música) y Homero Manzi (letra). Sur (Tango), 1948. http://www.todotango.com/musica/tema/372/Sur/.

"Un país disimulado al lado del Riachuelo". Diario La Nación, Buenos Aires, 13 de diciembre de 2006. https://www.lanacion.com. ar/867005-un-pais-disimulado-al-lado-del-riachuelo.

Villa, Mónica. José González Castillo. Militante de lo popular. Buenos Aires: Corregidor, 2015.

Yánez A., Parmenio. "El profesor Carlos Oliver Schneider, un precursor de la biología marina en Chile". Revista de Biología Marina (Valparaíso) (enero de 1950). https://revbiolmar.uv.cl/escaneados/2-97.pdf.

Yaverovski, Alejandro Martín. "Francia, Brasil, México y Argentina. Una propuesta de historia comparada para las Universidades Populares decimonónicas”. En Eje: Problemas filosóficos, históricos y epistemológicos en educación. VI Jornadas Nacionales y IV Latinoamericanas de Investigadores/as en Formación en Educación. Buenos Aires: Instituto de Investigaciones en Ciencias de la Educación, Universidad de Buenos Aires, 2018. 
Yaverovski, Alejandro Martín. "Dos palabras ¿Un concepto? Mil y un Concepciones para reflexionar en torno a los 100 años de las Universidades Populares". (Ponencia presentada en las Jornadas "Memorias, legados, disputas y prospectivas en Historia de la Educación. A 100 años de la Reforma Universitaria”. Córdoba: Universidad Nacional de Córdoba, 2018).

Yaverovski, Alejandro Martín. "Los ingenieros agrónomos en los primeros años de la Universidad Popular de la Boca". (Ponencia presentada en el XIII Congreso Iberoamericano de Historia de la Educación Latinoamericana CIHELA, Montevideo, 2018).

Yaverovski, Alejandro Martín. “Tomás Le Bretón: ¿exponente de una propuesta educativa alvearista?”. (Ponencia presentada a las XVI Jornadas Interescuelas/Departamentos de Historia. Mesa 59: "Teoría e Historia de la Educación Popular en Latinoamérica y América del Norte, siglos XIX y XX”, Universidad Nacional de Mar del Plata, 2017).

Para citar este artículo: Yaverovski, Alejandro Martín. "Tres Repúblicas Barriales y sus Universidades. Las Universidades Populares en la ciudad de Buenos Aires en el período de entreguerras: un esquema preliminar", Historia Caribe Vol. XVI No. 38 (Enero-Junio 2021): 35-80. DOI: https://doi.org/10.15648/hc.38.2021.2817 